\title{
De novo transcriptome analysis and comparative expression profiling of genes associated with the taste-modifying protein neoculin in Curculigo latifolia and Curculigo capitulata fruits
}

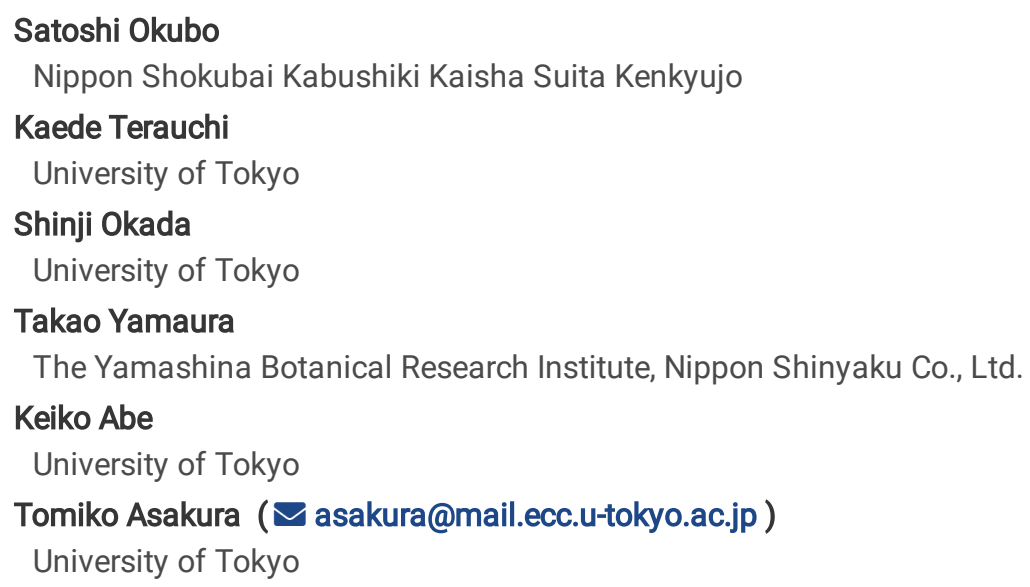

Version of Record: A version of this preprint was published at BMC Genomics on May 13th, 2021. See the published version at https://doi.org/10.1186/s12864-021-07674-3. 


\section{Abstract}

Background Curculigo latifolia is a perennial plant found in Southeast Asia whose fruits contain the taste-modifying protein neoculin, which binds to sweet receptors to make sour fruits taste sweet. Although neoculin is similar to Galanthus nivalis agglutinin (GNA), which contains mannose-binding sites in its sequence and 3D structure, neoculin lacks such sites and has no lectin activity. Whether the fruits of C. latifolia and other Curculigo plants contain neoculin and/or GNA family genes is unclear.

Results We performed de novo RNA-seq assembly of the fruits of $C$. latifolia and the related $C$. capitulata and analyzed the expression patterns of neoculin and neoculin-like genes in both species in detail. We assembled 85,697 transcripts from $C$. latifolia and 76,775 from $C$. capitulata using Trinity and annotated them using public databases. We identified 70,371 unigenes in C. latifolia and 63,704 in $C$. capitulata. In total, $38.6 \%$ of unigenes from $C$. latifolia and $42.6 \%$ from $C$. capitulata shared high similarity between the two species. We identified ten neoculin-related transcripts in C. latifolia and 15 in C. capitulata. Genes encoding both the basic and acidic subunits of neoculin were present in both plants. We aligned these 25 transcripts and generated a phylogenetic tree. Many orthologs in both species shared high similarity, despite the low number of common genes, suggesting that these genes likely existed before the two species diverged. The relative expression levels of these genes, as indicated by their transcript per million (TPM) values, differed considerably between the two species: the TPM values of neoculin genes were 60 times higher in C. latifolia than in C. capitulata, whereas those of GNA family members were 15,000 times lower in C. latifolia than in C. capitulata.

Conclusions The genetic diversity of the neoculin-related genes strongly suggests that neoculin genes underwent duplication during evolution. The marked differences in the expression profiles of neoculin-related genes between $C$. latifolia and $C$. capitulata could be due to mutations in regions involved in transcriptional regulation. Comprehensive analysis of the genes expressed in the fruits of these two Curculigo species helped elucidate the origin of neoculin at the molecular level.

\section{Background}

Curculigo latifolia (Hypoxidaceae family, formerly classified in the Liliaceae family) is a perennial plant found in Southeast Asia, especially the Malay peninsula [1, 2]. According to the Royal Botanic Gardens, Kew, there are 27 species of Curculigo [3]. The genetic diversity and morphology of Curculigo have long been of interest [4-7]. C. latifolia and C. capitulata were previously reclassified as members of the Molineria genus, but recent discussions have suggested that they should be returned to the Curculigo genus. Here, we use the traditional name, Curculigo.

C. latifolia and C. capitulata have a similar appearance (Fig. 1), but their flower and fruit morphology differ, and C. capitulata is more widely distributed than $C$. latifolia. Both species are diploids $(2 n=18 ; x=9)$ [8]. C. latifolia is self-incompatible [9], but $C$. capitulata plants from various botanical gardens in Japan have not been successfully crossed. The flowers, roots, stems, and leaves of Curculigo plants have traditionally been used as medicines [10-15]. Notably, unlike $C$. capitulata, C. latifolia fruits produce a taste-modifying protein, neoculin, that makes sour-tasting foods or water taste sweet $[1,16,17,18]$.

Neoculin itself has sweet taste and is 550 times sweeter than sucrose $(w / w)[19,20]$. Furthermore, neoculin has taste-modifying activity that converts sourness to sweetness; for example, sour lemon taste is changed to sweet orange. Neoculin is received by the human sweet taste receptor T1R2-T1R3 [21]. Moreover, sweetness is induced by water in the presence of neoculin, and some organic acids taste sweet after tasting of neoculin [22]. Neoculin consists of two subunits that form a heterodimer: the neoculin basic subunit (NBS), also called curculin [16], and the neoculin acidic subunit (NAS) [18, 23]. NBS is $11 \mathrm{kDa}$ and consists of 114 amino-acid residues [16, 24], while NAS is $13 \mathrm{kDa}$ and consists of 113 amino-acid residues. These subunits share $77 \%$ amino-acid identity [18]. Several important amino-acid residues that are responsible for the taste-modifying properties of neoculin have been identified: His 11 of NBS is responsible for $\mathrm{pH}$ dependent taste-modifying activity [25], and Arg48, Tyr65, Val72, and Phe94 function in the binding and activation of human sweet taste receptors [26]. Changes in the 3D structures of these proteins at these amino-acid residues are thought to contribute to the taste-modifying properties of neoculin $[27,28]$.

Lectins are proteins that recognize and bind to specific carbohydrate structures [29, 30]. Plant lectins are classified into 12 families. The GNA (Galanthus nivalis agglutinin) family of lectins, which are present in bulbs such as snowdrops (Galanthus nivalis) and daffodils (Narcissus pseudonarcissus)[31], are thought to function as defense or storage proteins. Both the amino-acid sequences and 3D structures of neoculin NBS and NAS are similar to those of GNA family members [32, 33], but NBS and NAS lack the mannose-binding site (MBS) and do not have lectin activity [34-36]. GNA family members in plants such as snowdrop contain one disulfide bond, which functions in intrasubunit bonding, but neoculin exhibits both intra-subunit bonding and one inter-subunit bond between NBS and NAS [32]. 
The fruit of $C$. latifolia contains $1.3 \mathrm{mg}$ neoculin per fruit [37] or $1.3 \mathrm{mg}$ per $1 \mathrm{~g}$ pulp [38]. This level is thought to be considerably higher than the levels of all proteins in typical edible fruits [39]. Although the taste-modifying activity of neoculin is well known, its role in $C$. latifolia is unknown. In addition, as neoculin is not a lectin, it not clear which lectins are expressed in $C$. latifolia fruit, especially lectins of the GNA family. In addition, whether other Curculigo species have neoculin or neoculin-like proteins is unknown.

Here, we compared the gene expression patterns in the fruits of $C$. latifolia and $C$. capitulata by RNA sequencing (RNA-seq). The aim of this study was to comprehensively analyze the two species from the viewpoint of amino-acid sequences and gene expression levels to shed light on the origin of neoculin.

\section{Results}

\section{Sequencing and de novo assembly}

We sequenced cDNA libraries from $C$. latifolia and $C$. capitulata using the Illumina HiSeq 2500 system. To analyze the data, we filtered out raw reads with average quality values $<20$, reads with $<50$ nucleotides, and reads with ambiguous ' $N$ ' bases. After removing adapter elements and filtering, we obtained 44,396,896 reads from C. latifolia and 43,863,400 from C. capitulata. High-quality reads from $C$. latifolia and $C$. capitulata were assembled into 85,697 and 76,775 contigs with a mean length of 775.14 bp and 743.71 bp, respectively, using Trinity 2.11. The distributions of transcript lengths and transcripts per million (TPM) values are shown in Additional File 1 and Additional File 2. The N50 values of $C$. latifolia and $C$. capitulata transcripts were 1,324 and 1,205, respectively (Table 1 ). Unigene clustering using CDHit revealed 70,371 unigenes in C. latifolia and 63,704 in C. capitulata (Table 1).

Table 1

Overview of de novo RNA-seq assembly of Curculigo latifolia and C. capitulata fruits.

\begin{tabular}{|lll|}
\hline & C. latifolia & C. capitulata \\
\hline High-quality reads & $44,396,896$ & $43,863,400$ \\
\hline Total Trinity genes & 69,446 & 63,951 \\
\hline Total Trinity unigenes & 70,371 & 63,704 \\
\hline Total Trinity transcripts & 85,697 & 76,775 \\
\hline GC (\%) & 44.0 & 45.6 \\
\hline N10 & 3,214 & 2,676 \\
\hline N20 & 2,460 & 2,103 \\
\hline N50 & 1,324 & 1,205 \\
\hline Total assembled bases & $66,426,868$ & $57,098,016$ \\
\hline
\end{tabular}

\section{Sequence annotation}

Low annotation rate of the transcripts: we aligned all transcripts with sequences in various protein databases including the nonredundant protein (NR) database of the National Center for Biotechnology Information (NCBI), RefSeq, UniProt/Swiss-Prot, and Clusters of Orthologous Groups of proteins (COG) and selected the top hits from these matches. Only 38,144 of 85,697 transcripts (44.5\%) in C. latifolia and 40,322 of 76,775 transcripts (52.5\%) in C. capitulata were annotated with a threshold of $1 \mathrm{e}^{-10}$ by performing BLASTx using the NR, RefSeq, UniProt, and COG databases. All annotations are listed in Additional File 3. The number of annotated transcripts for each database is listed in Table 2. The low annotation rate suggests that the two Curculigo species are significantly different from the model plants that supply much of the information in the public databases. 
Table 2

Number of functional annotations of the transcripts of Curculigo latifolia and C. capitulata fruits.

\begin{tabular}{|lll|}
\hline Annotated database & C. latifolia & C. capitulata \\
\hline COG ${ }^{1}$ & 11,875 & 12,448 \\
\hline RefSeq & 37,922 & 39,369 \\
\hline Uniprot & 36,783 & 38,901 \\
\hline NR $^{2}$ & 37,118 & 39,340 \\
\hline All four databases & 38,145 & 40,324 \\
\hline${ }^{1}$ COG: Clusters Groups of proteins. & & \\
\hline 2 NR: nonredundant protein databases of the National Center for Biotechnology Information. \\
\hline
\end{tabular}

Conservation among monocotyledons: we performed BLASTx search of the transcripts against the NR database, followed by Blast2GO [40]. We estimated the similarity of the two Curculigo species to various other species by counting the number of hits from each species from the results of BIAST searches (Fig. 2). The top six most highly homologous species were monocotyledons, like Curculigo, supporting the view that the list of the assembled Curculigo genes are highly similar to known monocotyledon genes. The top six homologous species were the same for $C$. latifolia and $C$. capitulata in terms of both species and rank.

Expression of functionally similar genes between two species: using the COG database, we classified 11,875 transcripts from $C$. latifolia and 12,448 from C. capitulata into functional categories (Fig. 3). No significant differences were observed between the two species. This result supports that these two species have functionally similar genes.

We analyzed the functions of the assembled transcripts via Gene Ontology (GO) analysis (Additional File 4). Again, no significant differences were observed between the two species. These results suggest that the repertoires of genes in the two species were similar to known genes.

\section{Comparative analysis of genes expressed in C. latifolia and C. capitulata fruits}

Using the unigene sequences, we analyzed the similarity of genes in C. latifolia and C. capitulata. We performed BLAST searches using each transcript from one species as the query sequence against all transcripts from the other species at $E$-values $1 \mathrm{e}^{-5}$ and selected the top hits. We defined unigenes with high similarity between the two species as 'common genes' and unigenes with low similarity between the species or present in only one species as 'unique genes'. In total, $38.6 \%$ of genes in C. latifolia and $42.6 \%$ of genes in $C$. capitulata were common genes (Fig. 4). The relatively small number of common genes between these species suggests that a long time has passed since their divergence. A long divergence time is consistent with the results of lineage analysis based on plastid DNA from Hypoxidaceae family members, which showed that the Curculigo genus belongs to a single clade, but $C$. latifolia and $C$. capitulata are not the most closely related species within this clade [5].

We investigated the proportions of annotated genes in these species using the COG, RefSeq, UniProt, and NR databases (shown in Table 2). Among the common genes, 17,260 and 17,139 genes were annotated ( $63.6 \%$ and $63.1 \%$ of common genes) in C. latifolia and $C$. capitulata, respectively. By contrast, there were 11,565 genes (26.8\% of unique genes) annotated unique genes in C. latifolia and 14,718 (40.3\% of unique genes) in $C$. capitulata. Thus, the annotation rate was higher for common genes than for unique genes despite the smaller number of common genes. Perhaps many of the genes common to both species are also common genes in the model plants that are mostly highly represented in the databases.

We then compared the expression profiles of 27,155 common genes in C. latifolia vs. C. capitulata. Although the sequences of the corresponding genes in $C$. latifolia and $C$. capitulata were similar, their expression profiles were not necessarily equivalent. Only 111 of the 27,155 common genes had TPM ratios $\geq 50$ (Table 3). Of these 111 genes, five were neoculin-related genes, meaning that the expression profiles of neoculin-related genes significantly differ between the two species. 
Table 3

Comparison of the expression profiles of Curculigo latifolia and C. capitulata.

\begin{tabular}{|c|c|c|c|c|c|}
\hline \multirow{2}{*}{$\begin{array}{l}\text { C. latifolia } \\
\text { TRYNITY_ID }\end{array}$} & \multicolumn{5}{|c|}{ C. capitulata } \\
\hline & RefSeq & TPM & TRYNITY_ID & RefSeq & TPM \\
\hline DN19492_c6_g1_i1 & $\begin{array}{l}\text { trans-resveratrol di-O- } \\
\text { methyltransferase }\end{array}$ & 36282 & DN19332_c0_g2_i1 & $\begin{array}{l}\text { trans-resveratrol di-O- } \\
\text { methyltransferase }\end{array}$ & 277 \\
\hline DN20774_c6_g2_i5 & $\begin{array}{l}\text { trans-resveratrol di-O- } \\
\text { methyltransferase }\end{array}$ & 31648 & DN20405_c1_g1_i2 & $\begin{array}{l}\text { trans-resveratrol di-O- } \\
\text { methyltransferase }\end{array}$ & 573 \\
\hline *DN22219_c0_g1_i1 & mannose-specific lectin-like & 7634 & *DN16562_c0_g1_i1 & mannose-specific lectin-like & 80 \\
\hline DN22040_c0_g1_i1 & chalcone synthase-like & 6483 & DN22230_c0_g1_i1 & chalcone synthase-like & 69 \\
\hline DN39489_c0_g1_i1 & cinnamoyl-CoA reductase 1-like & 4584 & DN43958_c0_g1_i1 & $\begin{array}{l}\text { cinnamoyl-CoA reductase 1- } \\
\text { like }\end{array}$ & 37 \\
\hline DN17418_c0_g1_i1 & $\begin{array}{l}\text { benzyl alcohol 0- } \\
\text { benzoyltransferase }\end{array}$ & 2848 & DN20771_c2_g1_i3 & $\begin{array}{l}\text { benzyl alcohol 0- } \\
\text { benzoyltransferase }\end{array}$ & 18 \\
\hline DN18625_c0_g1_i1 & glutelin type-A 1-like & 2641 & DN18515_c0_g1_i1 & glutelin type-A 1-like & 35 \\
\hline DN20161_c0_g1_i1 & probable polyamine oxidase 5 & 2333 & DN20921_c0_g1_i1 & $\begin{array}{l}\text { probable polyamine oxidase } \\
5\end{array}$ & 38 \\
\hline DN20171_c0_g1_i1 & $\begin{array}{l}\text { pyruvate decarboxylase } 1 \text { isoform } \\
\text { X1 }\end{array}$ & 2140 & DN19622_c0_g1_i1 & $\begin{array}{l}\text { pyruvate decarboxylase } 1 \\
\text { isoform X1 }\end{array}$ & 30 \\
\hline DN19390_c0_g1_i1 & $\begin{array}{l}\text { benzyl alcohol 0- } \\
\text { benzoyltransferase-like }\end{array}$ & 1721 & DN20336_c0_g1_i1 & $\begin{array}{l}\text { benzyl alcohol 0- } \\
\text { benzoyltransferase-like }\end{array}$ & 25 \\
\hline DN17288_c0_g1_i1 & $\begin{array}{l}\text { 5-methyltetrahydropteroyl- } \\
\text { triglutamate-homocysteine } \\
\text { methyltransferase } 1\end{array}$ & 1527 & DN20491_c0_g1_i4 & $\begin{array}{l}\text { 5-methyltetrahydropteroyl- } \\
\text { triglutamate-homocysteine } \\
\text { methyltransferase 2-like }\end{array}$ & 19 \\
\hline DN22101_c0_g1_i1 & cytochrome P450 71A1-like & 1130 & DN20591_c0_g1_i1 & cytochrome P450 71A1-like & 14 \\
\hline DN9054_c0_g2_i1 & $\begin{array}{l}\text { uncharacterized protein } \\
\text { LOC105052971 }\end{array}$ & 891 & DN20462_c0_g1_i1 & $\begin{array}{l}\text { uncharacterized protein } \\
\text { LOC105052971 }\end{array}$ & 16 \\
\hline DN19899_c1_g1_i5 & elongation factor 1-alpha-like & 720 & DN16211_c0_g1_i1 & $\begin{array}{l}\text { hypothetical protein } \\
\text { CARUB_v100096370mg, } \\
\text { partial }\end{array}$ & 11 \\
\hline DN39417_c0_g1_i1 & $\begin{array}{l}\text { palmitoyl-acyl carrier protein } \\
\text { thioesterase, chloroplastic-like }\end{array}$ & 659 & DN1125_c0_g1_i1 & $\begin{array}{l}\text { palmitoyl-acyl carrier protein } \\
\text { thioesterase, chloroplastic- } \\
\text { like }\end{array}$ & 0.89 \\
\hline DN8999_c0_g1_i1 & probable protein Pop3 & 657 & DN3239_c0_g1_i1 & probable protein Pop3 & 10 \\
\hline *DN16562_c0_g1_i1 & mannose-specific lectin-like & 652 & *DN16324_c0_g1_i1 & mannose-specific lectin-like & 8 \\
\hline DN20784_c0_g1_i1 & $\begin{array}{l}\text { mannan endo-1,4-beta- } \\
\text { mannosidase 5-like }\end{array}$ & 477 & DN20300_c0_g1_i1 & $\begin{array}{l}\text { mannan endo-1,4-beta- } \\
\text { mannosidase 5-like }\end{array}$ & 8 \\
\hline DN17063_c0_g1_i1 & $\begin{array}{l}\text { uncharacterized protein } \\
\text { LOC103705182 }\end{array}$ & 457 & DN15604_c0_g1_i1 & & 7 \\
\hline DN9763_c0_g1_i1 & $\begin{array}{l}\text { 4-hydroxyphenyl-pyruvate } \\
\text { dioxygenase }\end{array}$ & 441 & DN17419_c0_g1_i2 & $\begin{array}{l}\text { 4-hydroxyphenyl-pyruvate } \\
\text { dioxygenase }\end{array}$ & 6 \\
\hline DN15645_c0_g1_i1 & $\begin{array}{l}\text { hypothetical protein } \\
\text { PHAVU_005G042200g }\end{array}$ & 378 & DN19503_c0_g1_i2 & $\begin{array}{l}\text { uncharacterized protein } \\
\text { LOC103713005 }\end{array}$ & 4 \\
\hline DN39500_c0_g1_i1 & $\begin{array}{l}\text { uncharacterized protein } \\
\text { C24B11.05-like isoform X2 }\end{array}$ & 323 & DN15665_c0_g1_i2 & $\begin{array}{l}\text { uncharacterized protein } \\
\text { C24B11.05-like isoform X2 }\end{array}$ & 6 \\
\hline
\end{tabular}

*: neoculin-related transcripts (cf. Figure 5 and Additional File 5)

The common genes with TPM value $\geq 50$ between the two species, except when the TPM values of both genes is $<100$. The genes were sorted based on the TPM value of $C$. latifolia along with the corresponding genes of $C$. capitulata. Note that there were no cases of genes that were highly expressed in both species. This pattern strongly suggests changes in the gene expression regulatory system due to divergence of two species. 


\begin{tabular}{|c|c|c|c|c|c|}
\hline C. latifolia & & & C. capitulata & & \\
\hline DN16206_c0_g1_i1 & cytochrome P450 71A1-like & 295 & DN18399_c0_g1_i1 & cytochrome P450 71A1-like & 5 \\
\hline DN9770_c0_g1_i1 & Os09g0480700, partial & 278 & DN11365_c0_g1_i1 & Os09g0480700, partial & 3 \\
\hline DN20943_c2_g1_i1 & $\begin{array}{l}\text { LOW QUALITY PROTEIN: ATP- } \\
\text { citrate synthase beta chain protein } \\
\text { 1-like }\end{array}$ & 276 & DN20189_c1_g1_i6 & $\begin{array}{l}\text { LOW QUALITY PROTEIN: } \\
\text { ATP-citrate synthase beta } \\
\text { chain protein 1-like }\end{array}$ & 5 \\
\hline DN5031_c0_g1_i1 & & 265 & DN26197_c0_g1_i1 & & 3 \\
\hline DN19581_c0_g1_i1 & peroxidase 43 & 244 & DN20763_c0_g1_i7 & peroxidase 43 & 3 \\
\hline DN22200_c0_g1_i1 & & 237 & DN21279_c0_g3_i1 & & 0 \\
\hline DN16082_c0_g1_i1 & $\begin{array}{l}\text { uncharacterized protein } \\
\text { LOC105035694 }\end{array}$ & 230 & DN20815_c0_g1_i2 & $\begin{array}{l}\text { uncharacterized protein } \\
\text { LOC105035694 }\end{array}$ & 4 \\
\hline DN1821_c0_g1_i1 & $\begin{array}{l}\text { protein EARLY RESPONSIVE TO } \\
\text { DEHYDRATION 15-like }\end{array}$ & 213 & DN5863_c0_g3_i1 & $\begin{array}{l}\text { protein EARLY RESPONSIVE } \\
\text { TO DEHYDRATION 15-like }\end{array}$ & 1 \\
\hline DN21840_c4_g7_i1 & & 197 & DN46444_c0_g1_i1 & & 2 \\
\hline DN11489_c0_g1_i1 & & 189 & DN51079_c0_g1_i1 & & 3 \\
\hline DN21813_c0_g1_i1 & $\begin{array}{l}\text { protein kinase APK1B, } \\
\text { chloroplastic-like }\end{array}$ & 184 & DN20869_c0_g1_i9 & $\begin{array}{l}\text { protein kinase APK1B, } \\
\text { chloroplastic-like }\end{array}$ & 0.97 \\
\hline DN16611_c0_g1_i1 & & 163 & DN8161_c0_g1_i1 & & 2 \\
\hline DN12355_c0_g1_i1 & myb-related protein 306 -like & 160 & DN7266_c0_g1_i1 & myb-related protein 306-like & 3 \\
\hline DN18378_c0_g1_i1 & probable L-ascorbate peroxidase 4 & 158 & DN17994_c1_2_i1 & $\begin{array}{l}\text { probable L-ascorbate } \\
\text { peroxidase } 4\end{array}$ & 2 \\
\hline DN21677_c0_g1_i1 & $\begin{array}{l}\text { S-adenosylmethionine } \\
\text { decarboxylase proenzyme-like }\end{array}$ & 149 & DN15562_c0_g2_i1 & $\begin{array}{l}\text { S-adenosylmethionine } \\
\text { decarboxylase proenzyme- } \\
\text { like }\end{array}$ & 0.92 \\
\hline DN14830_c0_g1_i1 & NAC transcription factor 29-like & 135 & DN20428_c0_g1_i1 & $\begin{array}{l}\text { NAC transcription factor 29- } \\
\text { like }\end{array}$ & 0 \\
\hline DN14165_c0_g2_i1 & probable peroxygenase 4 & 131 & DN17339_c0_g1_i2 & probable peroxygenase 4 & 2 \\
\hline DN21840_c4_g4_i2 & & 130 & DN11729_c0_g1_i1 & & 2 \\
\hline DN39737_c0_g1_i1 & Glutathione peroxidase 2 & 127 & DN8347_c0_g1_i1 & Glutathione peroxidase 2 & 2 \\
\hline DN4928_c0_g1_i1 & & 124 & DN44794_c0_g1_i1 & & 1 \\
\hline DN20250_c0_g1_i1 & protein NRT1/ PTR FAMILY 5.6-like & 114 & DN29979_c0_g1_i1 & $\begin{array}{l}\text { protein NRT1/ PTR FAMILY } \\
\text { 5.6-like }\end{array}$ & 2 \\
\hline DN15628_c0_g1_i1 & formin-A-like & 103 & DN20575_c0_g1_i5 & formin-A-like & 0 \\
\hline DN21235_c2_g9_i1 & & 101 & DN9877_c0_g1_i1 & & 1 \\
\hline *DN19752_c0_g1_i1 & mannose-specific lectin 3-like & 33 & *DN18595_c0_g1_i1 & mannose-specific lectin 3-like & 2301 \\
\hline
\end{tabular}

*: neoculin-related transcripts (cf. Figure 5 and Additional File 5)

The common genes with TPM value $\geq 50$ between the two species, except when the TPM values of both genes is $<100$. The genes were sorted based on the TPM value of $C$. latifolia along with the corresponding genes of $C$. capitulata. Note that there were no cases of genes that were highly expressed in both species. This pattern strongly suggests changes in the gene expression regulatory system due to divergence of two species. 


\begin{tabular}{|c|c|c|c|c|c|}
\hline C. latifolia & & & C. capitulata & & \\
\hline DN16463_c0_g2_i2 & $\begin{array}{l}\text { LOW QUALITY PROTEIN: S- } \\
\text { norcoclaurine synthase-like }\end{array}$ & 16 & DN6989_c0_g1_i1 & $\begin{array}{l}\text { LOW QUALITY PROTEIN: S- } \\
\text { norcoclaurine synthase-like }\end{array}$ & 8393 \\
\hline DN32395_c0_g1_i1 & & 14 & DN4973_c0_g1_i1 & & 8765 \\
\hline DN19456_c0_g1_i1 & $\begin{array}{l}\text { polyphenol oxidase, chloroplastic- } \\
\text { like }\end{array}$ & 13 & DN20237_c3_g1_i1 & $\begin{array}{l}\text { polyphenol oxidase, } \\
\text { chloroplastic-like }\end{array}$ & 1496 \\
\hline DN14333_c0_g1_i1 & & 12 & DN13197_c0_g1_i1 & & 42047 \\
\hline DN55067_c0_g1_i1 & $\begin{array}{l}\text { defensin Ec-AMP-D1 } \\
\text { \{ECO:0000303| } \\
\text { PubMed:18625284\}-like }\end{array}$ & 9 & DN39416_c0_g1_i1 & $\begin{array}{l}\text { defensin Ec-AMP-D1 } \\
\text { \{ECO:0000303| } \\
\text { PubMed:18625284\}-like }\end{array}$ & 2475 \\
\hline DN5253_c0_g1_i1 & $\begin{array}{l}\text { Disease resistance-responsive } \\
\text { (dirigent-like protein) family } \\
\text { protein, putative }\end{array}$ & 9 & DN16870_c0_g2_i1 & $\begin{array}{l}\text { Disease resistance- } \\
\text { responsive (dirigent-like } \\
\text { protein) family protein, } \\
\text { putative }\end{array}$ & 547 \\
\hline DN1586_c0_g1_i1 & glycine-rich protein-like isoform X1 & 8 & DN39384_c0_g1_i1 & & 2895 \\
\hline DN23556_c0_g1_i1 & basic blue protein-like & 5 & DN14117_c0_g1_i1 & basic blue protein-like & 606 \\
\hline DN13618_c0_g1_i1 & $\begin{array}{l}\text { non-specific lipid-transfer protein 1- } \\
\text { like }\end{array}$ & 5 & DN13976_c0_g1_i1 & $\begin{array}{l}\text { lipid transfer protein } \\
\text { precursor }\end{array}$ & 655 \\
\hline DN465_c0_g2_i1 & $\begin{array}{l}\text { microsomal glutathione S- } \\
\text { transferase 3-like }\end{array}$ & 5 & DN4959_c0_g1_i1 & $\begin{array}{l}\text { microsomal glutathione S- } \\
\text { transferase 3-like }\end{array}$ & 246 \\
\hline DN21384_c3_g4_i1 & & 5 & DN17484_c0_g1_i1 & & 424 \\
\hline DN9003_c0_g1_i1 & dirigent protein 22-like isoform X1 & 5 & DN19511_c0_g1_i1 & dirigent protein 22-like & 834 \\
\hline DN4015_c0_g1_i1 & CASP-like protein 2A1 & 4 & DN4840_c0_g1_i1 & CASP-like protein 2A1 & 241 \\
\hline DN16618_c0_g1_i1 & $\begin{array}{l}\text { hypothetical protein } \\
\text { SORBIDRAFT_05g026700 }\end{array}$ & 3 & DN4999_c0_g1_i1 & $\begin{array}{l}\text { Bowman-Birk type trypsin } \\
\text { inhibitor-like isoform X2 }\end{array}$ & 5459 \\
\hline DN4834_c0_g2_i1 & xylem serine proteinase 1 -like & 3 & DN9966_c0_g1_i1 & subtilisin-like protease & 232 \\
\hline DN6907_c0_g1_i1 & $\begin{array}{l}\text { serine/threonine-protein kinase } \\
\text { CDL1-like }\end{array}$ & 3 & DN11871_c1_g1_i1 & $\begin{array}{l}\text { serine/threonine-protein } \\
\text { kinase CDL1-like }\end{array}$ & 183 \\
\hline DN17444_c0_g1_i1 & cytochrome P450 CYP82D47-like & 3 & DN20684_c0_g1_i1 & $\begin{array}{l}\text { cytochrome P450 } \\
\text { CYP82D47-like }\end{array}$ & 182 \\
\hline DN40485_c0_g3_i1 & $\begin{array}{l}\text { non-specific lipid-transfer protein 1- } \\
\text { like }\end{array}$ & 3 & DN39065_c0_g1_i1 & $\begin{array}{l}\text { non-specific lipid-transfer } \\
\text { protein 1-like }\end{array}$ & 1455 \\
\hline DN18380_c0_g1_i2 & conserved hypothetical protein & 3 & DN39186_c0_g1_i1 & $\begin{array}{l}\text { conserved hypothetical } \\
\text { protein }\end{array}$ & 654 \\
\hline DN31252_c0_g1_i1 & & 3 & DN12650_c0_g1_i1 & $\begin{array}{l}\text { non-specific lipid-transfer } \\
\text { protein-like }\end{array}$ & 283 \\
\hline DN42464_c0_g2_i1 & $\begin{array}{l}\text { alpha carbonic anhydrase 8-like, } \\
\text { partial }\end{array}$ & 3 & DN40148_c0_g1_i1 & $\begin{array}{l}\text { alpha carbonic anhydrase 7- } \\
\text { like }\end{array}$ & 235 \\
\hline DN13852_c0_g1_i1 & endoglucanase 6 & 3 & DN18579_c0_g1_i1 & endoglucanase 19-like & 707 \\
\hline DN39898_c0_g1_i1 & $\begin{array}{l}\text { oxygen-evolving enhancer protein } \\
3-1 \text {, chloroplastic-like }\end{array}$ & 2 & DN12932_c0_g1_i1 & $\begin{array}{l}\text { oxygen-evolving enhancer } \\
\text { protein } 3-1 \text {, chloroplastic- } \\
\text { like }\end{array}$ & 160 \\
\hline DN6056_c0_g1_i1 & $\begin{array}{l}\text { Calvin cycle protein CP12-1, } \\
\text { chloroplastic-like }\end{array}$ & 2 & DN12691_c0_g1_i1 & $\begin{array}{l}\text { calvin cycle protein CP12-1, } \\
\text { chloroplastic }\end{array}$ & 215 \\
\hline DN6093_c0_g1_i1 & & 2 & DN41578_c0_g1_i1 & & 170 \\
\hline \multicolumn{6}{|c|}{ *: neoculin-related transcripts (cf. Figure 5 and Additional File 5) } \\
\hline \multicolumn{6}{|c|}{$\begin{array}{l}\text { The common genes with TPM value } \geq 50 \text { between the two species, except when the TPM values of both genes is }<100 \text {. The genes } \\
\text { were sorted based on the TPM value of } C \text {. latifolia along with the corresponding genes of } C \text {. capitulata. Note that there were no cases } \\
\text { of genes that were highly expressed in both species. This pattern strongly suggests changes in the gene expression regulatory system } \\
\text { due to divergence of two species. }\end{array}$} \\
\hline
\end{tabular}




\begin{tabular}{llclll} 
DN17773_c0_g1_i1 & $\begin{array}{l}\text { uncharacterized protein } \\
\text { LOC105056845 }\end{array}$ & 2 & DN12165_c0_g1_i1 & $\begin{array}{l}\text { uncharacterized protein } \\
\text { LOC105056845 }\end{array}$ & 249 \\
\hline DN24151_c0_g1_i1 & ribonuclease 3-like & 2 & DN39292_c0_g1_i1 & ribonuclease 3-like & 389
\end{tabular}

\begin{tabular}{|c|c|c|c|c|c|}
\hline DN8678_c0_g1_i1 & $\begin{array}{l}\text { uncharacterized protein } \\
\text { LOC105056672 }\end{array}$ & 2 & DN4730_c0_g1_i1 & $\begin{array}{l}\text { uncharacterized protein } \\
\text { LOC105056672 }\end{array}$ & 116 \\
\hline DN19431_c2_g4_i1 & polyubiquitin 4-like, partial & 2 & DN20039_c0_g8_i1 & $\begin{array}{l}\text { hypothetical protein } \\
\text { PHAVU_003G1236000g, } \\
\text { partial }\end{array}$ & 2116 \\
\hline DN250_c1_g1_i1 & $\begin{array}{l}\text { probable glutathione S-transferase } \\
\text { parA }\end{array}$ & 2 & DN16559_c0_g1_i1 & $\begin{array}{l}\text { probable glutathione S- } \\
\text { transferase parA }\end{array}$ & 419 \\
\hline DN10676_c0_g1_i1 & $\begin{array}{l}\text { probable linoleate 9S-lipoxygenase } \\
5\end{array}$ & 2 & DN17658_c0_g1_i1 & $\begin{array}{l}\text { probable linoleate 9S- } \\
\text { lipoxygenase } 5\end{array}$ & 1644 \\
\hline DN8975_c0_g1_i1 & chitinase-like protein 1 & 2 & DN16475_c1_g1_i1 & chitinase-like protein 1 & 183 \\
\hline DN44393_c0_g1_i1 & $\begin{array}{l}\text { hypothetical protein } \\
\text { POPTR_0004s03650g }\end{array}$ & 2 & DN18495_c2_g1_i1 & $\begin{array}{l}\text { conserved hypothetical } \\
\text { protein }\end{array}$ & 2751 \\
\hline DN759_c0_g1_i1 & $\begin{array}{l}\text { CAS1 domain-containing protein 1- } \\
\text { like }\end{array}$ & 2 & DN21365_c0_g1_i1 & $\begin{array}{l}\text { CAS1 domain-containing } \\
\text { protein } 1 \text {-like isoform X2 }\end{array}$ & 183 \\
\hline DN30327_c0_g1_i1 & conserved hypothetical protein & 2 & DN23037_c0_g1_i1 & $\begin{array}{l}\text { conserved hypothetical } \\
\text { protein }\end{array}$ & 134 \\
\hline DN5572_c0_g1_i1 & $\begin{array}{l}\text { short-chain type } \\
\text { dehydrogenase/reductase-like }\end{array}$ & 2 & DN14194_c0_g1_i1 & $\begin{array}{l}\text { short-chain type } \\
\text { dehydrogenase/reductase- } \\
\text { like }\end{array}$ & 205 \\
\hline DN45139_c0_g1_i1 & putative germin-like protein 2 - 1 & 2 & DN21890_c0_g1_i1 & $\begin{array}{l}\text { putative germin-like protein } 2 \\
-1\end{array}$ & 111 \\
\hline DN22251_c0_g1_i1 & $\begin{array}{l}\text { xyloglucan endotransglucosylase/ } \\
\text { hydrolase protein 9-like }\end{array}$ & 2 & DN40495_c0_g2_i1 & $\begin{array}{l}\text { LOW QUALITY PROTEIN: } \\
\text { xyloglucan } \\
\text { endotransglucosylase/ } \\
\text { hydrolase protein 9-like }\end{array}$ & 131 \\
\hline DN56341_c0_g1_i1 & peroxidase 4-like & 1 & DN10149_c0_g1_i1 & $\begin{array}{l}\text { peptide-N4-(N-acetyl-beta- } \\
\text { glucosaminyl)asparagine } \\
\text { amidase A-like }\end{array}$ & 1301 \\
\hline DN56680_c0_g1_i1 & $\begin{array}{l}\text { peptide-N4-(N-acetyl-beta- } \\
\text { glucosaminyl)asparagine amidase } \\
\text { A-like }\end{array}$ & 1 & DN19920_c0_g1_i1 & peroxidase 4-like & 583 \\
\hline *DN307_c0_g2_i1 & mannose-specific lectin-like & 1 & *DN9931_c0_g1_i1 & mannose-specific lectin-like & 14867 \\
\hline
\end{tabular}

*: neoculin-related transcripts (cf. Figure 5 and Additional File 5)

The common genes with TPM value $\geq 50$ between the two species, except when the TPM values of both genes is $<100$. The genes were sorted based on the TPM value of $C$. latifolia along with the corresponding genes of $C$. capitulata. Note that there were no cases of genes that were highly expressed in both species. This pattern strongly suggests changes in the gene expression regulatory system due to divergence of two species. 


\begin{tabular}{|c|c|c|c|c|c|}
\hline C. latifolia & & & C. capitulata & & \\
\hline DN48085_c0_g1_i1 & $\begin{array}{l}\text { probable indole-3-acetic acid- } \\
\text { amido synthetase GH3.1 }\end{array}$ & 1 & DN19080_c1_g1_i1 & $\begin{array}{l}\text { probable indole-3-acetic acid- } \\
\text { amido synthetase GH3.1 }\end{array}$ & 107 \\
\hline DN46946_c0_g1_i1 & $\begin{array}{l}\text { chlorophyll a-b binding protein } 7 \text {, } \\
\text { chloroplastic-like }\end{array}$ & 1 & DN41884_c0_g1_i1 & $\begin{array}{l}\text { chlorophyll a-b binding } \\
\text { protein, chloroplastic }\end{array}$ & 141 \\
\hline DN4845_c0_g1_i1 & $\begin{array}{l}\text { chlorophyll a-b binding protein } \\
\text { CP26, chloroplastic-like }\end{array}$ & 1 & DN10575_c0_g1_i1 & $\begin{array}{l}\text { chlorophyll a-b binding } \\
\text { protein CP26, chloroplastic- } \\
\text { like }\end{array}$ & 353 \\
\hline DN23363_c0_g1_i1 & $\begin{array}{l}\text { uncharacterized protein } \\
\text { LOC105056050 }\end{array}$ & 1 & DN21609_c0_g1_i1 & $\begin{array}{l}\text { uncharacterized protein } \\
\text { LOC105056050 }\end{array}$ & 1612 \\
\hline *DN30823_c0_g1_i1 & mannose-specific lectin-like & 1 & *DN17363_c2_g1_i3 & mannose-specific lectin-like & 317 \\
\hline DN645_c0_g1_i1 & putative lipid-transfer protein DIR1 & 1 & DN12082_c0_g1_i1 & $\begin{array}{l}\text { putative lipid-transfer protein } \\
\text { DIR1 }\end{array}$ & 108 \\
\hline DN50661_c0_g1_i1 & $\begin{array}{l}\text { oxygen-evolving enhancer protein } \\
2 \text {, chloroplastic-like }\end{array}$ & 1 & DN14711_c0_g1_i1 & $\begin{array}{l}\text { oxygen-evolving enhancer } \\
\text { protein } 2 \text {, chloroplastic-like }\end{array}$ & 133 \\
\hline DN16663_c0_g1_i2 & & 1 & DN20564_c0_g1_i1 & & 642 \\
\hline DN41624_c0_g1_i1 & isocitrate lyase & 1 & DN15046_c0_g1_i1 & isocitrate lyase & 116 \\
\hline DN33923_c0_g1_i1 & $\begin{array}{l}\text { galactinol synthase 2-like isoform } \\
\mathrm{X} 1\end{array}$ & 1 & DN13705_c0_g1_i1 & galactinol synthase 1-like & 127 \\
\hline DN36400_c0_g1_i1 & putative cell wall protein & 0.98 & DN26021_c0_g1_i1 & putative cell wall protein & 117 \\
\hline DN53880_c0_g1_i1 & $\begin{array}{l}\text { uncharacterized protein } \\
\text { LOC105056050 }\end{array}$ & 0.93 & DN5177_c0_g1_i1 & $\begin{array}{l}\text { proactivator polypeptide-like } \\
1\end{array}$ & 644 \\
\hline DN6399_c0_g1_i1 & auxin-induced protein 22D-like & 0.93 & DN10469_c0_g1_i1 & $\begin{array}{l}\text { auxin-induced protein 22D- } \\
\text { like }\end{array}$ & 171 \\
\hline DN10569_c0_g2_i1 & & 0.91 & DN16356_c0_g1_i1 & & 1072 \\
\hline DN21646_c1_g1_i3 & protein HOTHEAD-like & 0.91 & DN14207_c0_g1_i1 & protein HOTHEAD-like & 330 \\
\hline DN22097_c0_g1_i1 & & 0.82 & DN9693_c0_g2_i1 & & 155 \\
\hline DN30250_c0_g1_i1 & polygalacturonase inhibitor & 0.64 & DN17486_c1_g1_i2 & Polygalacturonase inhibitor & 171 \\
\hline DN50985_c0_g1_i1 & $\begin{array}{l}\text { putative phytosulfokines } 6 \text { isoform } \\
\mathrm{X} 1\end{array}$ & 0.47 & DN22933_c0_g1_i1 & $\begin{array}{l}\text { putative phytosulfokines } 6 \\
\text { isoform X2 }\end{array}$ & 136 \\
\hline DN39567_c0_g2_i1 & profilin-1 & 0 & DN15886_c0_g1_i1 & profilin-1 & 615 \\
\hline DN5103_c0_g1_i1 & $\begin{array}{l}\text { trans-resveratrol di-O- } \\
\text { methyltransferase-like }\end{array}$ & 0 & DN39904_c0_g1_i1 & $\begin{array}{l}\text { trans-resveratrol di-O- } \\
\text { methyltransferase-like }\end{array}$ & 430 \\
\hline DN24431_c0_g6_i1 & $60 S$ ribosomal protein L24 & 0 & DN1942_c0_g1_i1 & $60 S$ ribosomal protein L24 & 278 \\
\hline DN3220_c0_g1_i1 & & 0 & DN1273_c0_g1_i1 & $\begin{array}{l}\text { chlorophyll a-b binding } \\
\text { protein } 6 \text {, chloroplastic }\end{array}$ & 264 \\
\hline DN16735_c0_g2_i2 & $\begin{array}{l}\text { uncharacterized protein } \\
\text { LOC105047938 }\end{array}$ & 0 & DN39063_c0_g1_i1 & $\begin{array}{l}\text { uncharacterized protein } \\
\text { LOC105047938 }\end{array}$ & 172 \\
\hline DN256_c0_g1_i2 & Os06g0133500 & 0 & DN16734_c1_g2_i1 & Os06g0133500 & 151 \\
\hline \multicolumn{6}{|c|}{ *: neoculin-related transcripts (cf. Figure 5 and Additional File 5) } \\
\hline \multicolumn{6}{|c|}{$\begin{array}{l}\text { The common genes with TPM value } \geq 50 \text { between the two species, except when the TPM values of both genes is }<100 \text {. The genes } \\
\text { were sorted based on the TPM value of } C \text {. latifolia along with the corresponding genes of } C \text {. capitulata. Note that there were no cases } \\
\text { of genes that were highly expressed in both species. This pattern strongly suggests changes in the gene expression regulatory system } \\
\text { due to divergence of two species. }\end{array}$} \\
\hline
\end{tabular}

Lectin genes expressed in C. latifolia and C. capitulata fruits

We previously demonstrated that $C$. latifolia fruits contain a taste-modifying protein comprising a heterodimer of NBS and NAS that is similar to lectins in the GNA family. We therefore determined the number of lectin genes expressed in the fruits of $C$. latifolia and $C$. 
capitulata that were categorized into each of the 12 lectin families to better understand the general outline of the GNA family genes in these species. To determine the number of lectin genes, we performed tBLASTn searches against all transcripts in each species using the sequences of 12 representative lectins as queries [41] (Table 4). In both species, the largest lectin family was the GNA family, including the neoculin (NBS and NAS) genes. Ten of the 45 lectin genes in C. latifolia and 13 of the 49 lectin genes in C. capitulata were GNA family members. Thus, we analyzed the many GNA family genes in these species, including the neoculin genes, in more detail.

Table 4

The number of lectin genes predicted using tBLASTn in Curculigo latifolia and $C$. capitulata fruits.

\begin{tabular}{|llll|}
\hline Lectin domain & Model lectin & C. latifolia & C. capitulata \\
\hline ABA domain & Agaricus bisporus agglutinin & 0 & 0 \\
\hline Amaranthin domain & Amaranthus caudatus agglutinin & 0 & 0 \\
\hline CRA domain & Robinia pseudoacacia & 3 & 4 \\
\hline Cyanovirin domain & Nostoc ellipsosporum agglutinin & 0 & 0 \\
\hline EUL domain & Euonymus europaeus agglutinin & 1 & 1 \\
\hline GNA domain & Galanthus nivalis agglutinin & 10 & 13 \\
\hline Hevein domain & Hevea brasiliensis agglutinin & 3 & 2 \\
\hline JRL domain & Artocarus integer agglutinin & 9 & 4 \\
\hline Legume domain & Glycine max agglutinin & 8 & 16 \\
\hline LysM domain & Brassica juncea LysM domain & 1 & 1 \\
\hline Nictaba domain & Nicotiana tabacum agglutinin & 10 & 8 \\
\hline Ricin-B domain & Ricinus communis agglutinin & 0 & 0 \\
\hline Total number of lectin & genes & 45 & 49 \\
\hline
\end{tabular}

\section{GNA family and neoculin-related transcripts}

First, we constructed a phylogenetic tree using the deduced protein sequences of 17 transcripts of well-known GNA family members and 25 neoculin-related transcripts (10 transcripts from $C$. latifolia and 15 from $C$. capitulata; Fig. 5); the method used for sequence selection is shown in Additional File 5. The TPM values (calculated by RSEM) are listed after the transcript IDs. An alignment of all sequences is shown in Additional File 6. The $C$. latifolia transcript DN16562_c0_g1_i1 is a good match for NBS, and DN16562_c0_g1_i2 is a good match for NAS, except for one amino-acid substitution (Additional File 7); these transcripts are referred to as NBS and NAS hereafter. The neoculinrelated transcripts formed groups different from that of the known GNA family members. Neoculin-like sequences formed one group that included NBS and NAS (named the 'neoculin group') as well as two other large groups (group 1 and group 2) (Fig. 5).

In each group, we detected neoculin-related orthologous transcripts with high similarity between $C$. Iatifolia and $C$. capitulata. The existence of many orthologs in each species, combined with the presence of relatively few common genes (comprising approximately $40 \%$ of all transcripts in both species; Fig. 4), is noteworthy. We inferred that these orthologs probably existed before the divergence of the two species, and their amino-acid differences probably arose afterward. Genetic diversity is beneficial for plants, including Curculigo, due to their lack of mobility. It would be interesting to determine whether Curculigo plants other than C. latifolia and $C$. capitulata contain neoculinrelated genes, especially genes in the neoculin group.

Of the genes in the neoculin group, highly similar sequences such as those of the NBS and NAS genes were present in $C$. latifolia, and their orthologs were identified in C. capitulata. Notably, although NBS and NAS genes were highly expressed in C. latifolia, their orthologs were only weakly expressed in C. capitulata (DN16324_c0_g1_i1 and DN16324_c0_g1_i2). The TPM values of NBS and NASgenes in C. latifolia were 652 and 624, respectively: that is, the expression levels of NBS and NAS were approximately the same. This result is in agreement with the finding that these proteins form a heterodimer [18]. Although DN9931_c0_g1_i1 of $C$. capitulata was highly expressed, with a TPM value of 14,867 (the fifth highest expression level among C. capitulata transcripts), its ortholog (DN307_c0_g1_i1, D307_c0_g2_i1) was expressed at a very low level in $C$. latifolia. Curiously, both in the neoculin group and in groups 1 and 2 , in cases where there were orthologs in both species, if a gene was highly expressed in one species, its ortholog was weakly expressed in the other species; there were no cases 
of genes that were highly expressed in both species. The data shown in Table 3 also support this pattern. These results strongly suggest changes in the gene expression regulatory system due to divergence of two species.

Next, we aligned the deduced amino-acid sequences of the proteins in the neoculin group (Fig. 6a). We divided the sequences into nine regions, including the regions removed by mRNA processing and three MBS-like regions: $\mathrm{N}$ pro-sequence (N-Pro), $\mathrm{N}$-terminal (N-term), MBS1, inter1, MBS2, inter2, MBS3, C-terminal (C-term), and C pro-sequence (C-Pro). In these regions, His11 of NBS, an essential residue for the $\mathrm{pH}$-dependent taste-modifying activity of neoculin, is present in the N-term regions of NBS. DN16562_c0_g1_i1 of $C$. latifolia and DN16324_c0_g1_i1 of C. capitulata. By contrast, DN9931_c0_g1_i1 of C. capitulata and DN307_c0_g1_i1 and D307_c0_g2_i1 of C. latifolia (abbreviated 'DN9931') did not have His11, but rather Tyr11, like NAS. In addition, Cys77 and Cys109, which form an intermolecular disulfide bond between NBS and NAS, are present in the inter2 and C-term regions in both species. However, these residues were absent in DN9931. Thus, it is likely that DN9931 does not form dimers.

Four residues are responsible for the binding and activation of the human sweet receptor: Arg48, Tyr65, Val72, and Phe94 [26]. Although Tyr65 and Val72 were identified in DN9931, Leu48 and Val94 were not present in this protein. The lack of His11 and these four indispensable residues, as well as the lack of dimerization, indicate that D9931 does not have a sweet taste or taste-modifying properties. Indeed, a preliminary test indicated that $C$. capitulata fruits did not have a sweet taste or taste-modifying properties despite the high expression level of DN9931_c0_g1_i1 (data not shown). Three sites similar to the MBS are present in the MBS1, MBS2, and MBS3 regions of this protein. Although the essential residues of the MBS were not conserved in NBS or NAS, all of them were conserved in DN9931_c0_g1_i1, marking DN9931_c0_g1_i1 as likely to be a lectin.

Based on this alignment, we investigated the amino-acid residue substitution in each region compared with each reference sequence: NBS or NAS (Additional File 8). The amino-acid substitution rate with reference to NBS is shown in the heatmap in Fig. 6b. Between the NBS series and the NAS series, $18-27 \%$ of substitutions occurred in the overall regions from the N-term region to C-term region (23\%, 26 of 114 residues in NBS). The highest rate was $27 \%$ in the MBS2 region, followed by $24 \%$ in the inter2 and C-term regions. In the DN9931 series, the highest substitution rate was $53 \%$ in the C-term region, followed by the MBS3 region (44\%) and inter2 region (43\%). These results suggest that the region from inter 2 to $\mathrm{C}$-term is the primary region of sequence diversity in the neoculin group.

\section{Biochemical analysis}

We extracted proteins from C. latifolia and C. capitulata fruits and carried out SDS-PAGE, followed by Coomassie brilliant blue (CBB) staining and immunoblotting using anti-NBS and anti-NAS antibodies (Fig. 7). After CBB staining, we detected an 11-kDa band representing NBS and a 13-kDa band representing NAS from C. latifolia (Fig. 7a). For C. capitulata, we detected an 11-kDa band and many smaller bands. One of these smaller bands was probably DN9931_c0_g1_i1, which had a high TPM value. Immunoblotting confirmed the identity of the bands containing NBS and NAS in C. latifolia fruits. However, no bands were confirmed in C. capitulata fruits (Fig. 7b), perhaps because NBS and NAS are expressed at very low levels in this species, as reflected by their low TPM values (as described above). The amino-acid sequence of the C-term region, which is recognized by the antibody, was very different in DN9931_c0_g1_i1 compared to both NBS and NAS, which is consistent with the finding that the proteins detected by CBB staining were not detected by immunoblotting.

\section{Discussion}

C. latifolia and C. capitulata contain many neoculin-related genes, which are similar within and between species. This diversity of neoculinrelated genes is thought to result from gene duplication, which is known to contribute to plant evolution [41-47]. Such gene duplication might place some genes under the same transcriptional regulation. The NBS and NAS genes are likely paralogs that arose due to tandem duplication. The characteristics of NBS and NAS genes in $C$. latifolia and $C$. capitulata are summarized in Table 5. Both $C$. latifolia and $C$. capitulata contained neoculin (NBS and NAS) transcripts, and the sequences of the DN9931 series transcripts matched those of active GNA family members. However, their expression levels in the two plant species were very different.

There was a notable difference in the expression level of these genes in C. latifolia and C. capitulata. C. latifolia fruit contains $1.3 \mathrm{mg}$ neoculin per $1 \mathrm{~g}$ of pulp. Because neoculin is 550 times as sweet as sucrose [19,20], $1 \mathrm{~g}$ of $C$. latifolia fruit pulp is estimated to be as sweet as $715 \mathrm{mg}$ of sucrose. Therefore, $C$. latifolia fruits taste sweet. The TPM values of the neoculin genes in $C$. capitulata were only $1 / 60$ those in C. latifolia. Therefore, C. capitulata fruits are estimated to contain approximately $22 \mathrm{ngg}^{-1}$ of neoculin and to be as sweet as $12 \mathrm{mg}$ of sucrose. Based on this content, it is likely that $C$. capitulata fruits do not taste sweet, as confirmed in a preliminary test. Thus, neoculin levels, and therefore taste, differ greatly between these fruits. The taste of $C$. latifolia fruit could strongly influence its survival strategies. For example, the sweet taste of neoculin may facilitate the spreading of $C$. latifolia seeds by animals. 
Table 5

Summary of neoculin group transcripts in fruits of two Curculigo species.

\begin{tabular}{|c|c|c|c|c|c|c|c|}
\hline & Transcript ID & $\begin{array}{l}\text { Reference } \\
\text { transcript }\end{array}$ & $\begin{array}{l}\text { No. of } \\
\text { substitution } \\
\text { (amino } \\
\text { acid) }\end{array}$ & $\begin{array}{l}\text { Heterodimerization } \\
\text { (no. of Cys) }\end{array}$ & $\begin{array}{l}\text { Lectin } \\
\text { activity } \\
\text { (no. of } \\
\text { MBS*) }^{*}\end{array}$ & $\begin{array}{l}\text { Taste } \\
\text { modification }\end{array}$ & $\begin{array}{l}\text { Expression } \\
\text { (TPM) }\end{array}$ \\
\hline \multirow[t]{4}{*}{$\begin{array}{l}\text { C. } \\
\text { latifolia }\end{array}$} & $\begin{array}{l}\text { DN16562_c0_g1_i1 } \\
\text { (NBS) }\end{array}$ & NBS & 0 & $\begin{array}{l}\text { Yes } \\
(4)\end{array}$ & $\begin{array}{l}\text { No } \\
(0)\end{array}$ & Yes & $\begin{array}{l}\text { High } \\
(652)\end{array}$ \\
\hline & $\begin{array}{l}\text { DN16562_c0_g1_i2 } \\
\text { (NAS) }\end{array}$ & NAS & 1 & $\begin{array}{l}\text { Yes } \\
(4)\end{array}$ & $\begin{array}{l}\text { No } \\
(0)\end{array}$ & Yes & $\begin{array}{l}\text { High } \\
(624)\end{array}$ \\
\hline & DN307_c0_g2_i1 & DN9931_c0_g1_i1 & 1 & $\begin{array}{l}\text { Unknown } \\
\text { (2) }\end{array}$ & $\begin{array}{l}\text { Unknown } \\
\text { (3) }\end{array}$ & Unknown & $\begin{array}{l}\text { Very low } \\
(1.4)\end{array}$ \\
\hline & DN307_c0_g1_i1 & DN9931_c0_g1_i1 & 1 & $\begin{array}{l}\text { Unknown } \\
\text { (2) }\end{array}$ & $\begin{array}{l}\text { Unknown } \\
\text { (3) }\end{array}$ & Unknown & $\begin{array}{l}\text { Very low } \\
(0.4)\end{array}$ \\
\hline \multirow[t]{3}{*}{$\begin{array}{l}\text { C. } \\
\text { capitulata }\end{array}$} & DN16324_c0_g1_i1 & NBS & 6 & $\begin{array}{l}\text { Probably Yes } \\
\text { (4) }\end{array}$ & $\begin{array}{l}\text { Probably } \\
\text { No } \\
\text { (0) }\end{array}$ & $\begin{array}{l}\text { Probably } \\
\text { Yes }\end{array}$ & $\begin{array}{l}\text { Low } \\
(8.0)\end{array}$ \\
\hline & DN16324_c0_g1_i2 & NAS & 0 & $\begin{array}{l}\text { Probably Yes } \\
\text { (4) }\end{array}$ & $\begin{array}{l}\text { Probably } \\
\text { No } \\
(0)\end{array}$ & $\begin{array}{l}\text { Probably } \\
\text { Yes }\end{array}$ & $\begin{array}{l}\text { low } \\
(10.8)\end{array}$ \\
\hline & DN9931_c0_g1_i1 & DN9931_c0_g1_i1 & - & $\begin{array}{l}\text { Unknown } \\
\text { (2) }\end{array}$ & $\begin{array}{l}\text { Unknown } \\
\text { (3) }\end{array}$ & $\begin{array}{l}\text { Unknown } \\
\text { (Fruits have } \\
\text { no activity) }\end{array}$ & $\begin{array}{l}\text { Very high } \\
\text { (14867) }\end{array}$ \\
\hline
\end{tabular}

The structure of the taste-modifying protein miraculin is similar to those of the soybean Kunitz trypsin inhibitor and thaumatin, a sweet protein with an a-amylase or trypsin-inhibitor-like structure. Similarly, neoculin has a similar structure to lectin, a common molecular structure in plants [48-54]. Trypsin inhibitors, amylase inhibitors, and lectins are commonly expressed in fruits and seeds. The diversity of these proteins arose from gene duplications and mutations during evolution. It appears that during the process of evolution, neoculin, miraculin, and thaumatin happened to acquire sweetness or taste-modifying activity for humans.

Lectins are thought to play important protective and storage roles in common plants. Thus, the high expression levels of lectin genes in $C$. capitulata fruits are likely to reflect their important roles in this plant. Conversely, the low expression levels of neoculin genes in $C$.

capitulata suggest that the compound is less useful in this plant. Similarly, in contrast to C. capitulata, active GNA family genes were barely expressed in $C$. latifolia fruits. Neoculin genes were highly expressed in $C$. latifolia but weakly expressed in $C$. capitulata despite the similar appearance of the two plants (Fig. 1). Perhaps these physiological differences are due to mutation of the cis-elements in these genes. Ciselements, including promoters, enhancers, and silencers, are very important in regulation of gene expression [41, 55-58]. The different expression levels of related genes in $C$. latifolia vs. $C$. capitulata could be caused by mutations in their cis-elements. For example, the ciselements of NBS and NAS genes may have mutated after the divergence of the two species, or perhaps these genes acquired mutations or lost cis-elements during the gene duplication that led to the divergence, leading to different expression patterns. Analyzing genomic information about these two species might help verify this notion.

\section{Conclusions}

RNA-seq analysis of $C$. latifolia and $C$. capitulata fruits revealed the presence of numerous neoculin-like genes. Among the various neoculin-related genes that arose through gene duplication, several mutations accumulated, resulting in the genes encoding NBS and NAS. These proteins form the heterodimeric protein neoculin, which has taste-modifying activity in humans. Our comprehensive investigation of the genes expressed in the fruits of these two Curculigo species helped uncover the origin of neoculin at the molecular level. 


\section{Methods}

\section{Plant materials}

C. latifolia (voucher ID 26092) was obtained from the Research Center for Medicinal Plant Resources, National Institutes of Biomedical Innovation, Health, and Nutrition (originally from Indonesia). C. capitulata (voucher ID 31481) was obtained from The Naito Museum of Pharmaceutical Science and Industry. The plants were cultivated in a greenhouse at the Yamashina Botanical Research Institute. Photographs of the fruits of these plants are shown in Fig. 1.

\section{Fruit setting}

C. latifolia flowers were pollinated by hand in the morning on the first day of flowering. C. capitulata flowers were placed in $50 \mathrm{ppm}$ of $1-$ naphthylacetic acid (NAA) in the mornings of both the first and second days of flowering. At $\sim 60$ days after flowering, mature fruits were harvested and immediately soaked in RNA later ${ }^{\text {TM }}$ solution (Thermo Fisher Scientific, MA. USA). The fruits were stored at $-80^{\circ} \mathrm{C}$ until use. The samples were ground into a powder in liquid nitrogen prior to RNA extraction. Total RNA was extracted from the frozen samples using the phenol-SDS method, and poly $(A)^{+}$mRNA was purified using an mRNA Purification Kit (Amersham Biosciences, Buckinghamshire, UK). Sequencing

mRNA sequencing was performed by Hokkaido System Science Co., Ltd. (Hokkaido, Japan). A cDNA library was generated using a TruSeq RNA Sample Prep Kit v2 (Illumina, Inc., CA. USA) and sequenced on the Illumina HiSeq 2500 system (Paired-End, unstranded). The raw reads were cleaned using cutadapt1.1 [59] and trimmomatic0.32 [60]. We removed adapter sequences, low-quality sequences (reads with ambiguous ' $N$ ' bases), and reads with $Q$-value $<20$ bases. Sequences smaller than 50 bases were eliminated. The high-quality reads were assembled into contigs using Trinity2.11 [61] with default options. We quantified transcript levels as transcripts per million (TPM) values using Bowtie1.12 [62] and RSEM (RNA-Seq by Expectation-Maximization) [63] in the Trinity package.

\section{Sequence clustering}

The assembled sequences were compared against the NCBI NR, prot-plant from RefSeq, and UniProt databases with an E-value $<1 \mathrm{e}^{-10}$. BLAST analysis was performed using BLAST version 2.2.31. CD-Hit (cd-hit-est) $[64,65]$ was used for clustering with the option of threshold (-c) 0.9 to obtain unigenes.

Comparison of gene expression in C. capitulata vs. C. latifolia fruits

To compare the transcripts in C. capitulata vs. C. latifolia fruits, a BLASTn search was performed with $E$-value $<1 \mathrm{e}^{-5}$ using each transcript from one species as the query sequence against all transcripts from the other species, and then the best hits were selected.

Identification of lectin gene transcripts in C. capitulata and C. latifolia fruits

A tBLASTn search (E-value $<1 \mathrm{e}^{-4}$; other options set to the default) was performed against all transcripts in $C$. capitulata and $C$. latifolia fruits with the following protein sequences as the queries, which represent each plant lectin family [41]: Agaricus bisporus agglutinin (UniProtKB/Swiss-Prot: Q00022.3-ABA), Amaranthus caudatus agglutinin (GenBank: AAL05954.1-amaranthin), Robinia pseudoacacia chitinase-related agglutinin (GenBank: ABL98074.1-CRA), Nostoc ellipsosporum agglutinin (UniProtKB/Swiss-Prot: P81180.2-cyanovirin), Euonymus europaeus agglutinin (GenBank: ABW73993.1-EUL), Galanthus nivalis agglutinin (UniProtKB/Swiss-Prot: P30617.1-GNA), Hevea brasiliensis agglutinin (GenBank: ABW34946.1-hevein), Artocarpus integer agglutinin (GenBank: AAA32680.1-JRL), Glycine max agglutinin (UniProtKB/Swiss-Prot: P05046.1-legume lectin), Brassica juncea LysM domain (GenBank: BAN83772.1-LysM), Nicotiana tabacum agglutinin (GenBank: AAK84134.1-Nictaba), and the lectin chain of Ricinus communis agglutinin (GenBank: PDB: 2AAI_B-ricin B). The top hits were selected.

\section{Phylogenetic analysis of GNA family proteins}

The sequences of 17 well-known GNA family proteins and species of origin were selected according to Shimizu-lbuka et al. [36]. The ASA, Allium sativum (garlic) (1BWU); GNA, Galanthus nivalis (snowdrop) (1MSA); and NPL, and Narcissus pseudonarcissus (wild daffodil) (1NPL) sequences were obtained from the Protein Data Bank. Others sequences were selected from GenBank as follows: PRA, Polygonatum roseum (AY899824); PMA, Polygonatum multiflorum (Solomon's seal) (U44775); CMA, Clivia miniata (kaffir lily) (L16512); ZCA, Zephyranthes candida (autumn zephyr lily) (AF527385); AAA, Allium ascalonicum (shallot) (L12172); ACA, Allium cepa (onion) (AY376826); AUA, Allium ursinum (ramsons) (U68531); THC, Tulipa hybrid cultivar (tulip) (U23043); ZOA, Zingiber officinale (ginger) (AY657021); ACO, Ananas comosus (pineapple) (AY098512); AKA, Amorphophallus konjac (konjac) (AY191004); DPA, Dioscorea polystachya (yam tuber) (AB178475); CHC, Cymbidium hybrid cultivar (cymbidium) (U02516); and EHA, Epipactis helleborine (broad-leaved helleborine) (U02515). These 17 sequences were aligned using ClustalW [66]. 


\section{Biochemical analysis}

SDS-PAGE was carried out using fruit extracts from C. latifolia and C. capitulata. The proteins were confirmed by Coomassie brilliant blue (CBB) staining. Protein gel blotting was carried out using anti-NAS or anti-NBS antibodies [38,67], which were targeted to the C-terminus of NAS or NBS, respectively. Preparation and purification of fruit extracts were performed as described previously [18, 38]. Each $0.1 \mathrm{~g}$ pulp sample was treated with $0.5 \mathrm{~mL}$ of $0.5 \mathrm{M} \mathrm{NaCl}$ to obtain an extract, which was combined with the appropriate volume of buffer containing 2-mercaptoethanol for SDS-PAGE. $5 \mu \mathrm{L}$ and $20 \mu \mathrm{L}$ of fruit extract from $C$. latifolia and $C$. capitulata was subjected to SDS-PAGE and CBB staining and $20 \mu \mathrm{L}$ and $10 \mu \mathrm{L}$ was subjected to immunoblotting, respectively.

\section{List of abbreviations}

AAA, Allium ascalonicum agglutinin; ACA, Allium cepa agglutinin; ACO, Ananas comosus lectin; AKA, Amorphophallus konjac agglutinin; ASA, Allium sativum agglutinin; AUA, Allium ursinum agglutinin; $\mathrm{CHC}$, Cymbidium hybrid cultivar agglutinin; CMA, Clivia miniata agglutinin; COG, Cluster of Orthologous Groups; DPA, Dioscorea polystachya agglutinin; EHA, Epipactis helleborine agglutinin; GNA, Galanthus nivalis agglutinin; GO, Gene Ontology; NAA, 1-naphthylacetic acid; NAS, neoculin acidic subunit; NCBI, the National Center for Biotechnology Information; NBS, neoculin basic subunit; NGS, next generation sequencing; NPL, Narcissus pseudonarcissus lectin; PMA, Polygonatum multiflorum agglutinin; PRA, Polygonatum roseum agglutinin; THC, Tulipa hybrid cultivar lectin; ZOA, Zingiber officinale agglutinin; TPM, transcripts per million; ZCA, Zephyranthes candida agglutinin.

\section{List Of Abbreviations}

AAA, Allium ascalonicum agglutinin; ACA, Allium cepa agglutinin; ACO, Ananas comosus lectin; AKA, Amorphophallus konjac agglutinin; ASA, Allium sativum agglutinin; AUA, Allium ursinum agglutinin; $\mathrm{CHC}$, Cymbidium hybrid cultivar agglutinin; CMA, Clivia miniata agglutinin; COG, Cluster of Orthologous Groups; DPA, Dioscorea polystachya agglutinin; EHA, Epipactis helleborine agglutinin; GNA, Galanthus nivalis agglutinin; GO, Gene Ontology; NAA, 1-naphthylacetic acid; NAS, neoculin acidic subunit; NCBI, the National Center for Biotechnology Information; NBS, neoculin basic subunit; NGS, next generation sequencing; NPL, Narcissus pseudonarcissus lectin; PMA, Polygonatum multiflorum agglutinin; PRA, Polygonatum roseum agglutinin; THC, Tulipa hybrid cultivar lectin; ZOA, Zingiber officinale agglutinin; TPM, transcripts per million; ZCA, Zephyranthes candida agglutinin.

\section{Declarations}

\section{Ethics approval and consent to participate}

Not applicable

\section{Consent for publication}

Not applicable

\section{Availability of data and materials}

The raw data and processed data from this study have been uploaded to the NCBI Gene Expression Omnibus (GSE151377) and are available in the NCBI database under accession number PRJNA635640, https://www.ncbi.nlm.nih.gov/bioproject/635640

\section{Competing interests}

The authors declare that they have no competing interests.

\section{Funding}

This study was supported by the Cross-ministerial Strategic Innovation Promotion Program (Grant No. 14532924; K.A.), a Grant-in-Aid for Scientific Research B (Grant No. 19300248; T.A.) from the Society for the Promotion of Science in Japan and Adaptable and Seamless Technology transfer Program through Target-driven R\&D (A-STEP) from Japan Science and Technology Agency to T.A. (Grant No.JPMJTR194F).

\section{Authors' contributions}


$\mathrm{TA}^{*}$ conceived the study and participated in the design of all experiments. S Okubo, KT, S Okada, TY, and KA analyzed and interpreted data. $S$ Okubo and TY cultivated plants and performed sample preparation. S Okubo and S Okada performed biological experiments. S Okubo and KT wrote the manuscript. KA discussed the experiments and manuscript. All authors read and approved the final manuscript.

\section{Acknowledgements}

We are grateful to the late Dr. Kosaburo Nishi of Research Center for Medicinal Plant Resources (Tsukuba Division), National Institutes of Biomedical Innovation, Health and Nutrition, for kindly providing the Curculigo latifolia plants. We also thank Hiroshi Morita, the Director of The Naito Museum of Pharmaceutical Science and Industry, for kindly providing the Curculigo capitulata plants. Computations were partially performed on the NIG supercomputer.

\section{Authors' information}

Satoshi Okubo and Kaede Terauchi contributed equally to this work.

\section{References}

1. Burkill IH. A dictionary of the economic products of the Malay Peninsula. London: Crown Agents for the Colonies; 1966. pp. 713-4

2. Perry LM. Medicinal plants of East and Southeast Asia. Cambridge: MIT Press; 1895. p. 12.

3. Plants of the World Online. http://www.plantsoftheworldonline.org/. Accessed May 172020.

4. Kocyan A. The discovery of polyandry in Curculigo (Hypoxidaceae): implications for androecium evolution of asparagoid monocotyledons. Ann Bot. 2007;100(2):241-8.

5. Kocyan A, Snijman DA, Forest F, Devey DS, Freudenstein JV, Wiland-Szymańska J, et al. Molecular phylogenetics of Hypoxidaceaeevidence from plastid DNA data and inferences on morphology and biogeography. Mol Phylogenet Evol. 2011;60(1):122-36.

6. Liu KW, Xie GC, Chen LJ, Xiao XJ, Zheng YY, Cai J, et al. Sinocurculigo, a new genus of Hypoxidaceae from China based on molecular and morphological evidence. PLoS One. 2012;7(6):e38880.

7. Ranjbarfard A, Saleh G, Abdullah NAP, Kashiani P. Genetic diversity of lemba (Curculigo latifolia) populations in Peninsular Malaysia using ISSR molecular markers. Australian Journal of Crop Science. 2014;8(1):9-17.

8. Eksomtramage L, Kwandarm M, Purintavaragul C. Karyotype of some Thai Hypoxidaceae species. Songklanakarin J Sci Technol. 2013;35(4):379-82.

9. Okubo S, Yamada M, Yamaura T, Akita T. Effects of the pistil size and self-incompatibility on fruit production in Curculigo latifolia (Liliaceae). J Japan Soc Hort Sci. 2010;79(4):354-9.

10. Asif M. A review on phytochemical and ethnopharmacological activities of Curculigo orchioides. Mahidol University Journal of Pharmaceutical Sciences. 2012;39(3-4):1-10.

11. Babaei N, Abdullah NAP, Saleh G, Abdullah TL. An efficient in vitro plantlet regeneration from shoot tip cultures of Curculigo latifolia, a medicinal plant. ScientificWorldJournal. 2014;2014:275028.

12. Ishak NA, Ismail M, Hamid M, Ahmad Z, Abd Ghafar SA. Antidiabetic and hypolipidemic activities of Curculigo latifolia fruit: root extract in high fat fed diet and low dose STZ induced diabetic rats. Evid Based Complement Alternat Med. 2013;2013:601838.

13. Li S, Yu JH, Fan YY, Liu QF, Li ZC, Xie ZX, et al. Structural elucidation and total synthesis of three 9-torlignans from Curculigo capitulata. J Org Chem. 2019;84(9):5195-202.

14. Nie Y, Dong X, He Y, Yuan T, Han T, Rahman K, et al. Medicinal plants of genus Curculigo: traditional uses and a phytochemical and ethnopharmacological review. J Ethnopharmacol. 2013;147(3):547-63.

15. Wang KJ, Zhu CC, Di L, Li N, Zhao YX. New norlignan derivatives from Curculigo capitulata. Fitoterapia. 2010;81(7):869-72.

16. Yamashita H, Theerasilp S, Aiuchi T, Nakaya K, Nakamura Y, Kurihara Y. Purification and complete amino acid sequence of a new type of sweet protein taste-modifying activity, curculin. J Biol Chem. 1990;265(26):15770-5.

17. Nakajima K, Asakura T, Oike H, Morita Y, Shimizu-lbuka A, Misaka T, et al. Neoculin, a taste-modifying protein, is recognized by human sweet taste receptor. Neuroreport. 2006;17(12):1241-4.

18. Shirasuka Y, Nakajima K, Asakura T, Yamashita H, Yamamoto A, Hata S, et al. Neoculin as a new taste-modifying protein occurring in the fruit of Curculigo latifolia. Biosci Biotechnol Biochem. 2004;68(6):1403-7.

19. Kant R. Sweet proteins-potential replacement for artificial low calorie sweeteners. Nutr J. 2005;4:5. 
20. Yamashita H, Akabane T, Kurihara Y. Activity and stability of a new sweet protein with taste-modifying action, curculin. Chem Senses. 1995;20(2):239-43.

21. Koizumi A, Nakajima K, Asakura T, Morita Y, Ito K, Shmizu-lbuka A, et al. Taste-modifying sweet protein, neoculin, is received at human T1R3 amino terminal domain. Biochem Biophys Res Commun. 2007;358(2):585-9.

22. Nakajima K, Koizumi A, lizuka K, Ito K, Morita Y, Koizumi T, et al. Non-acidic compounds induce the intense sweet taste of neoculin, a taste-modifying protein. Biosci Biotechnol Biochem. 2011;75(8):1600-2.

23. Suzuki M, Kurimoto E, Nirasawa S, Masuda Y, Hori K, Kurihara Y, et al. Recombinant curculin heterodimer exhibits taste-modifying and sweet-tasting activities. FEBS Lett. 2004;573(1-3):135-8.

24. Abe K, Yamashita H, Arai S, Kurihara Y. Molecular cloning of curculin, a novel taste-modifying protein with a sweet taste. Biochim Biophys Acta. 1992;1130(2):232-4.

25. Nakajima K, Yokoyama K, Koizumi T, Koizumi A, Asakura T, Terada T, et al. Identification and modulation of the key amino acid residue responsible for the $\mathrm{pH}$ sensitivity of neoculin, a taste-modifying protein. PLoS One. 2011;6(4):e19448.

26. Koizumi T, Terada T, Nakajima K, Kojima M, Koshiba S, Matsumura Y, et al. Identification of key neoculin residues responsible for the binding and activation of the sweet taste receptor. Sci Rep. 2015;5:12947.

27. Morita Y, Nakajima K, lizuka K, Terada T, Shimizu-lbuka A, Ito K, et al. pH-dependent structural change in neoculin with special reference to its taste-modifying activity. Biosci Biotechnol Biochem. 2009;73(11):2552-5.

28. Ohkubo T, Tamiya M, Abe K, Ishiguro M. Structural basis of pH dependence of neoculin, a sweet taste-modifying protein. PLoS One. 2015;10(5):e0126921.

29. Van Damme EJM, Peumans WJ, Barre A, Rougé P. Plant lectins: a composite of several distinct families of structurally and evolutionary related proteins with diverse biological roles. Critical Reviews in Plant Sciences. 1998;17:575-692.

30. Van Damme EJM, Lannoo N, Peumans WJ. Plant lectins. Advances in Botanical Research: Elsevie; 2008. pp. 107-209.

31. Barre A, Van Damme EJM, Peumans WJ, Rougé P. Structure-function relationship of monocot mannose-binding lectins. Plant Physiol. 1996;112(4):1531-40.

32. Shimizu-lbuka A, Morita Y, Terada T, Asakura T, Nakajima K, Iwata S, et al. Crystal structure of neoculin: insights into its sweetness and taste-modifying activity. J Mol Biol. 2006;359(1):148-58.

33. Kurimoto E, Suzuki M, Amemiya E, Yamaguchi Y, Nirasawa S, Shimba N, et al. Curculin exhibits sweet-tasting and taste-modifying activities through its distinct molecular surfaces. J Biol Chem. 2007;282(46):33252-6.

34. Barre A, Van Damme EJM, Peumans WJ, Rougé P. Curculin, a sweet-tasting and taste-modifying protein, is a non-functional mannosebinding lectin. Plant Mol Biol. 1997;33(4):691-8.

35. Harada S, Otani H, Maeda S, Kai Y, Kasai N, Kurihara Y. Crystallization and preliminary X-ray diffraction studies of curculin. A new type of sweet protein having taste-modifying action. J Mol Biol. 1994;238(2):286-7.

36. Shimizu-Ibuka A, Nakai Y, Nakamori K, Morita Y, Nakajima K, Kadota K, et al. Biochemical and genomic analysis of neoculin compared to monocot mannose-binding lectins. J Agric Food Chem. 2008;56(13):5338-44.

37. Nakajo S, Akabane T, Nakaya K, Nakamura Y, Kurihara Y. An enzyme immunoassay and immunoblot analysis for curculin, a new type of taste-modifying protein: cross-reactivity of curculin and miraculin to both antibodies. Biochim Biophys Acta. 1992;1118(3):293-7.

38. Okubo S, Asakura T, Okubo K, Abe K, Misaka T, Akita T. Neoculin, a taste-modifying sweet protein, accumulates in ripening fruits of cultivated Curculigo latifolia. J Plant Physiol. 2008;165(18):1964-9.

39. Standard tables of food composition in Japan - 2015 - (Seventh revised version) 2015. MEXT. https://www.mext.go.jp/en/policy/science_technology/policy/title01/detail01/1374030.htm. Accessed May 172020.

40. Götz S, García-Gómez JM, Terol J, Williams TD, Nagaraj SH, Nueda MJ, et al. High-throughput functional annotation and data mining with the Blast2GO suite. Nucleic Acids Res. 2008;36(10):3420-35.

41. De Schutter K, Tsaneva M, Kulkarni SR, Rougé P, Vandepoele K, Van Damme EJM. Evolutionary relationships and expression analysis of EUL domain proteins in rice (Oryza sativa). Rice (N Y). 2017;10(1):26.

42. Cannon SB, Mitra A, Baumgarten A, Young ND, May G. The roles of segmental and tandem gene duplication in the evolution of large gene families in Arabidopsis thaliana. BMC Plant Biol. 2004;4:10.

43. Copley SD. Evolution of new enzymes by gene duplication and divergence. FEBS J. 2020;287(7):1262-83.

44. Dang L, Van Damme EJM. Genome-wide identification and domain organization of lectin domains in cucumber. Plant Physiol Biochem. 2016;108:165-76. 
45. Fukushima K, Fang X, Alvarez-Ponce D, Cai H, Carretero-Paulet L, Chen C, et al. Genome of the pitcher plant Cephalotus reveals genetic changes associated with carnivory. Nat Ecol Evol. 2017;1(3):59.

46. Panchy N, Lehti-Shiu M, Shiu SH. Evolution of gene duplication in plants. Plant Physiol. 2016;171(4):2294-316.

47. Yan J, Li G, Guo X, Li Y, Cao X. Genome-wide classification, evolutionary analysis and gene expression patterns of the kinome in Gossypium. PLoS One. 2018;13(5):e0197392.

48. de Vos AM, Hatada M, van der Wel H, Krabbendam H, Peerdeman AF, Kim SH. Three-dimensional structure of thaumatin I, an intensely sweet protein. Proc Natl Acad Sci U S A. 1985;82(5):1406-9.

49. Kurihara Y. Characteristics of antisweet substances, sweet proteins, and sweetness-inducing proteins. Crit Rev Food Sci Nutr. 1992;32(3):231-52.

50. Liu JJ, Sturrock R, Ekramoddoullah AK. The superfamily of thaumatin-like proteins: its origin, evolution, and expression towards biological function. Plant Cell Rep. 2010;29(5):419-36.

51. Petre B, Major I, Rouhier N, Duplessis S. Genome-wide analysis of eukaryote thaumatin-like proteins (TLPs) with an emphasis on poplar. BMC Plant Biol. 2011;11:33.

52. Selvakumar P, Gahloth D, Tomar PP, Sharma N, Sharma AK. Molecular evolution of miraculin-like proteins in soybean Kunitz superfamily. J Mol Evol. 2011;73(5-6):369-79.

53. Theerasilp S, Hitotsuya H, Nakajo S, Nakaya K, Nakamura Y, Kurihara Y. Complete amino acid sequence and structure characterization of the taste-modifying protein, miraculin. J Biol Chem. 1989;264(12):6655-9.

54. Witty M, Higginboyham JD. Thaumatin. Florida, USA: CRC Press, Inc.; 1994. pp. 20-35.

55. Jiang SY, Ma Z, Ramachandran S. Evolutionary history and stress regulation of the lectin superfamily in higher plants. BMC Evol Biol. 2010;10:79.

56. Lambin J, Asci SD, Dubiel M, Tsaneva M, Verbeke I, Wytynck P, et al. OsEUL lectin gene expression in rice: stress regulation, subcellular localization and tissue specificity. Front Plant Sci. 2020;11:185.

57. Li XQ. Developmental and environmental variation in genomes. Heredity (Edinb). 2009;102(4):323-9.

58. Wittkopp PJ, Kalay G. Cis-regulatory elements: molecular mechanisms and evolutionary processes underlying divergence. Nat Rev Genet. 2011;13(1):59-69.

59. Martin M. Cutadapt removes adapter sequences from high-throughput sequencing reads. EMBnet.journal. 2011;17(1).

60. Bolger AM, Lohse M, Usadel B. Trimmomatic: a flexible trimmer for Illumina sequence data. Bioinformatics. 2014;30(15):2114-20.

61. Grabherr MG, Haas BJ, Yassour M, Levin JZ, Thompson DA, Amit I, et al. Trinity: reconstructing a full-length transcriptome without a genome from RNA-seq data. Nat Biotechnol. 2013;29(7):644-52.

62. Langmead B, Trapnell C, Pop M, Salzberg SL. Ultrafast and memory-efficient alignment of short DNA sequences to the human genome. Genome Biol. 2009;10(3):R25.

63. Li B, Dewey CN. RSEM: accurate transcript quantification from RNA-seq data with or without a reference genome. BMC Bioinformatics. $2011 ; 12: 323$.

64. Fu L, Niu B, Zhu Z, Wu S, Li W. CD-HIT: accelerated for clustering the next-generation sequencing data. Bioinformatics. 2012;28(23):3150-2.

65. Li W, Godzik A. Cd-hit: a fast program for clustering and comparing large sets of protein or nucleotide sequences. Bioinformatics. 2006;22(13):1658-9.

66. Larkin MA, Blackshields G, Brown NP, Chenna R, McGettigan PA, McWilliam H, et al. Clustal W and Clustal X version 2.0. Bioinformatics. 2007;23(21):2947-8.

67. Nakajima K, Asakura T, Maruyama J, Morita Y, Oike H, Shimizu-lbuka A, et al. Extracellular production of neoculin, a sweet-tasting heterodimeric protein with taste-modifying activity, by Aspergillus oryzae. Appl Environ Microbiol. 2006;72(5):3716-23.

\section{Additional Files}

Additional File 1. Supplemental Figure 1. Length distribution of the assembled transcripts (>1 TPM) from Curculigo latifolia (purple) and $C$. capitulata (orange) fruits.

Additional File 2. Supplemental Figure 2. Distribution of transcripts per million (TPM) values of the assembled transcripts from Curculigo latifolia (purple) and C. capitulata (orange) fruits. 
Average, Median and Mode of $C$. latifolia were 11.7, 1.6 and 2, respectively, and those of $C$. capitulata, 13.0, 1.9 and 2, respectively.

Additional File 3. Supplemental annotation. Transcripts from Curculigo latifolia and C. capitulata fruits were annotated by BLASTx (E-value

$<1 \mathrm{e}^{-10}$ ) against the NCBI NR, RefSeq, UniProt, and COG databases. Expression values (TPM), unigenes clustered by CD-Hit, and the unique or common genes from $C$. capitulata or $C$. latifolia were also included.

Additional File 4. Supplemental Figure 3. GO annotation of transcripts from Curculigo latifolia (purple) and C. capitulata (orange) fruits.

In total, 25,372 (C. latifolia) and 27,484 (C. capitulata) transcripts were classified by GO term. No significant differences were observed between the two species.

Additional File 5. Supplemental Table 1. Selection of sequences for phylogenetic analysis using BLAST search of transcripts from Curculigo latifolia and C. capitulata fruits.

The query sequences were the amino-acid sequences (AA) of GNA (UniProtKB/Swiss-Prot: P30617.1) and the nucleotide sequences (nucl) and AA of NBS (GenBank: X64110.1, GenBank: CAA45476.1) and NAS (GenBank: AB167079.1, GenBank: BAD29946.1). Each top hit was selected. The contigs that were selected for each query and used as neoculin-related sequences in phylogenetic analysis (Figure 5$)$ are indicated by checkmarks $(\sqrt{ })$.

Additional File 6. Supplemental Figure 4. Amino-acid sequence alignment of 10 Curculigo latifolia transcripts, 15 C. capitulata transcripts, and 17 well-known GNA family members used in the phylogenetic analysis shown in Figure 5.

Additional File 7. Supplemental Figure 5. Comparison of the amino-acid sequences of neoculin (NBS and NAS) in public databases and the Curculigo latifolia proteins identified in the present study.

Amino-acid residues that differ between NBS and NAS are shown in blue for NBS residues and red for NAS residues. Asn2 of DN16562_c0_g1_i2 was the only residue that differed from NAS, which has Ser at position 2 (GenBank: BAD29946.1). These de novo assemblies were good matches with the known sequences (NBS and NAS). This level of matching supports the accuracy of the assembly.

Additional File 8. Supplemental Table 2. Numbers of amino-acid residue substitutions in neoculin group proteins.

The values show the number of substituted amino-acid residues in each region. The transcripts were divided into nine regions, including $\mathrm{N}$ Pro, N-term, MBS1, inter1, MBS2, inter2, MBS3, C-term and C-Pro, the regions removed by processing, the $\mathrm{N}$ - or C-terminal regions, the mannose-binding sites MBS 1 to 3 , and the regions between the MBSs. "A" indicates residues of NAS different from those of NBS. "B" indicates residues of NBS different from those of NAS. "C" indicates residues different from those of both NBS and NAS. "D" indicates the residues only present in DN9931_c0_g1_i1.

\section{Figures}
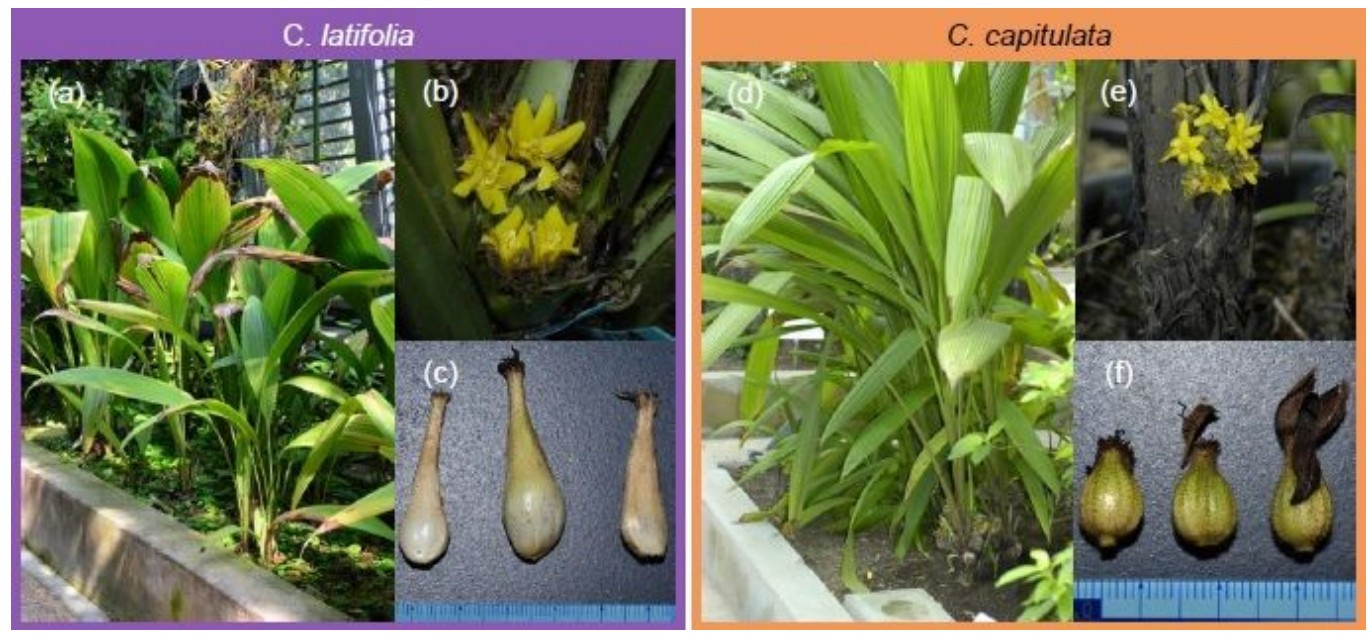

Figure 1 
Photographs of Curculigo latifolia and C. capitulata. Curculigo latifolia $(a-c)$ and C. capitulata $(d-f)$ in the greenhouse at the Yamashina Botanical Research Institute. (b and e) Inflorescences; (c and f) fruits.

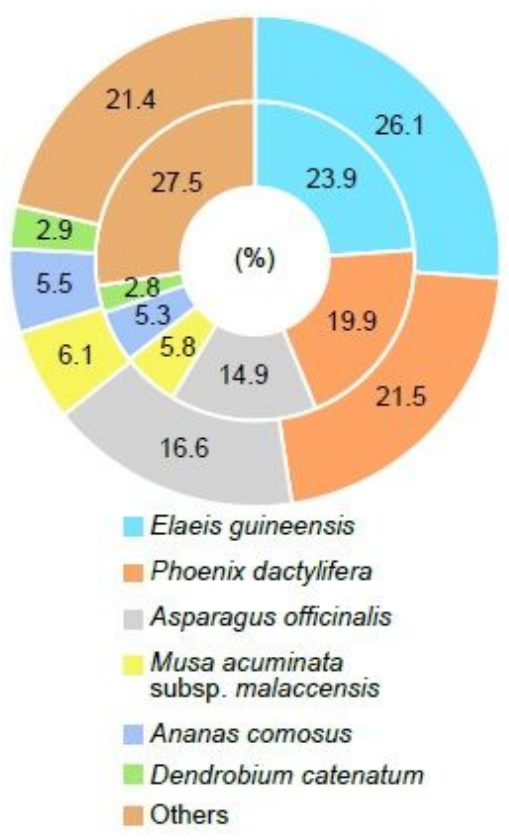

\section{Figure 2}

The assembled Curculigo latifolia and C. capitulata are highly similar to known monocotyledon genes. The percentage of species in Curculigo latifolia (outer circle) and C. capitulata (inner circle) was obtained from the results of BLAST search against the NR database. The top six most highly homologous species were monocotyledons, like Curculigo. 


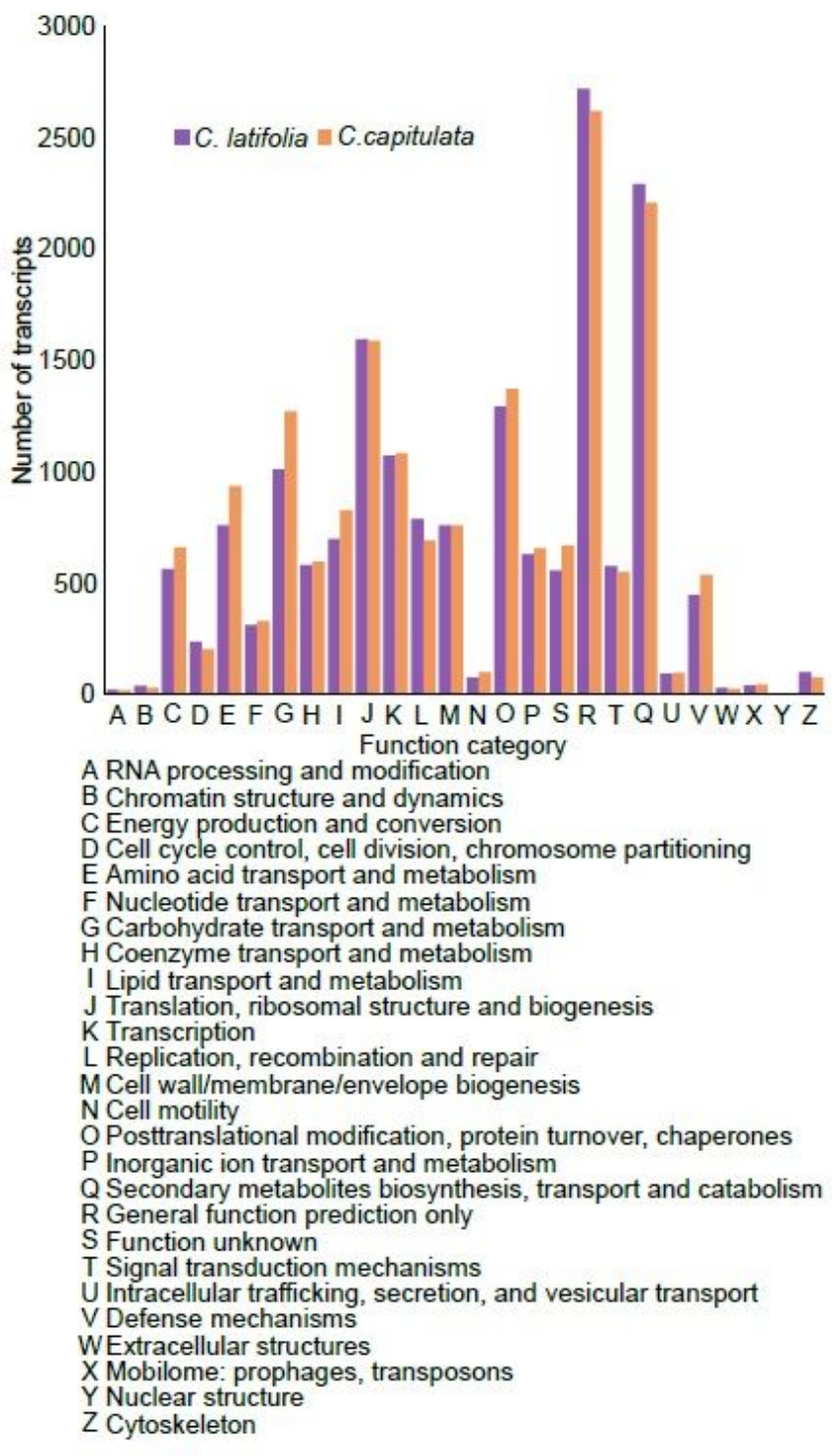

\section{Figure 3}

Curculigo latifolia and C. capitulata have functionally similar genes. Functional classification of transcripts of these two species were performed using the COG database. In total, 11,875 (C. latifolia) and 12,448 (C. capitulata) transcripts were grouped into 26 COG categories (A to Z). No significant differences were observed between the two species. 


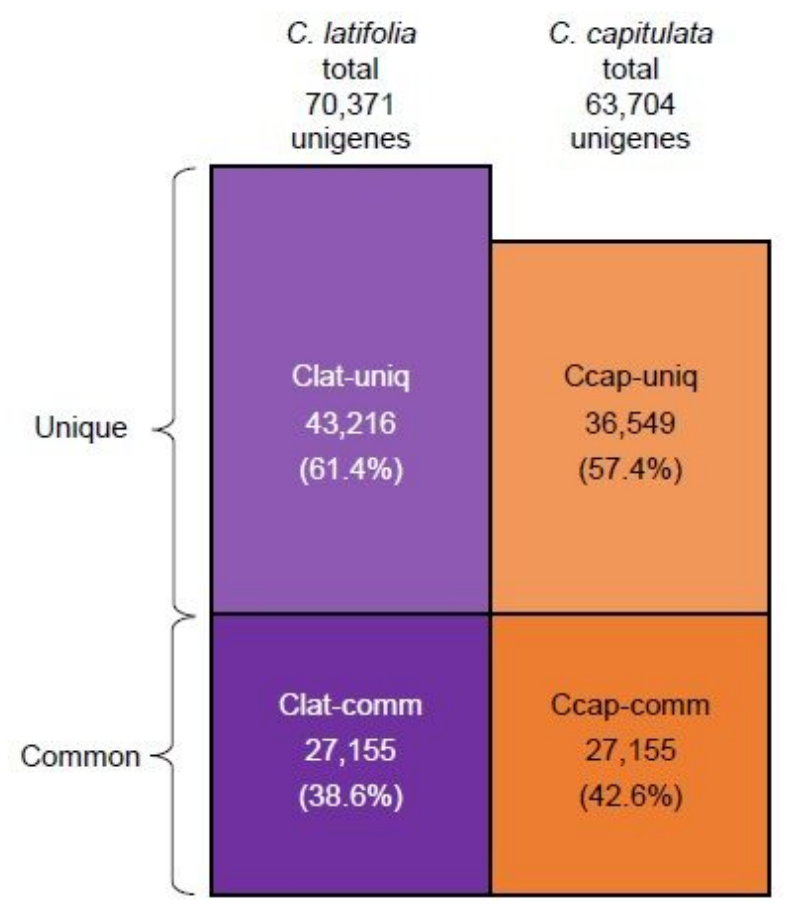

\section{Figure 4}

Majority of unigenes of Curculigo latifolia and C. capitulata are unique genes with low similarity. The number of unigenes based on the sequence similarity between Curculigo latifolia and C. capitulata fruits were investigated. The number of high similar unigenes, common genes, (Clat-comm: common genes of C. latifolia, and Ccap-comm: common genes of C. capitulata) and unigenes with low similarity, unique genes, (Clat-uniq: unique genes of $\mathrm{C}$. latifolia, and Ccap-uniq unique genes of C. capitulata). 


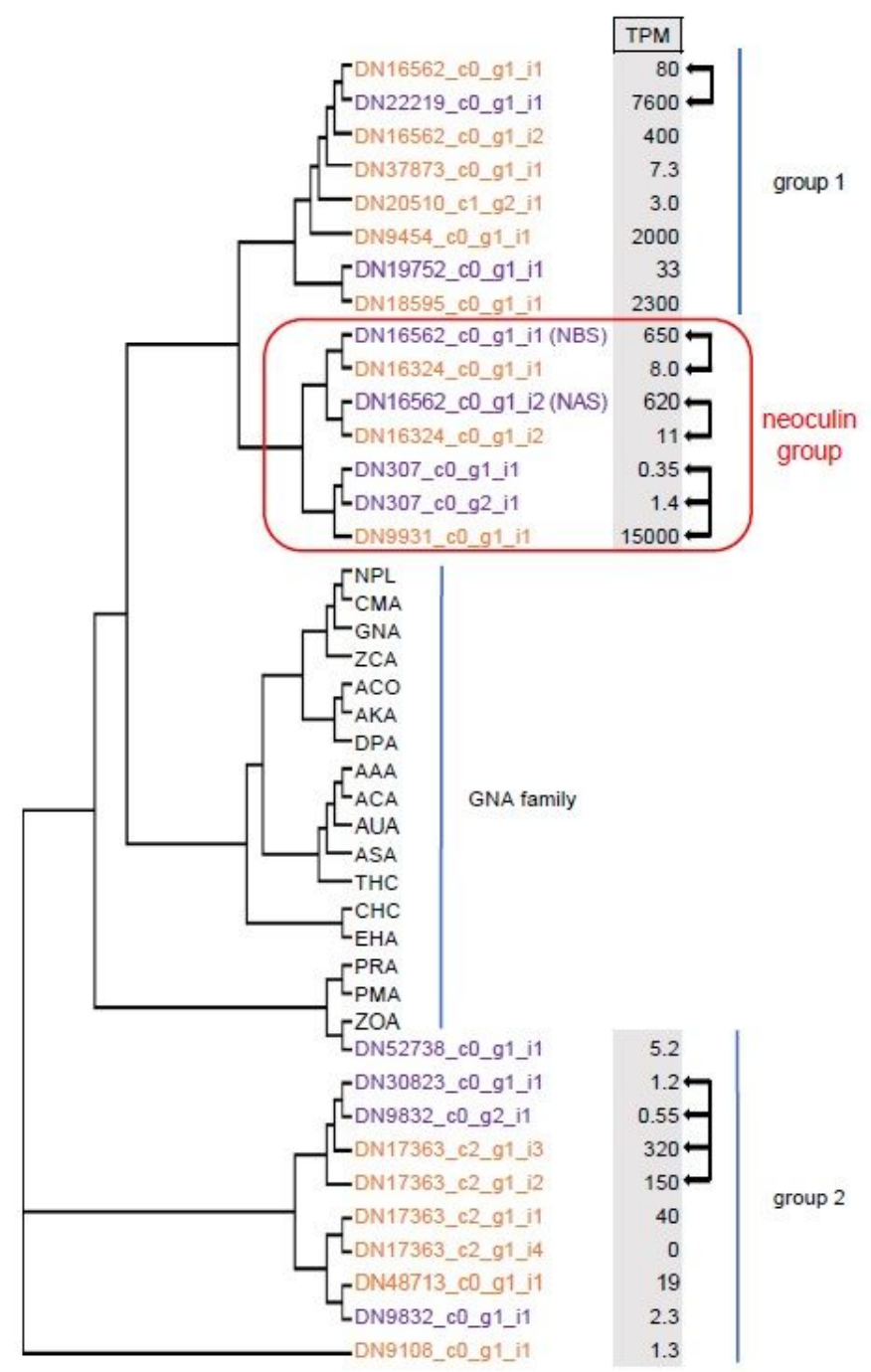

\section{Figure 5}

Phylogenetic analysis of neoculin-related and GNA family genes. NGS transcript IDs for C. latifolia and C. capitulata are shown in purple and orange, respectively. DN16562_c0_g1_i1 and DN16562_c0_g1_i2 of C. latifolia correspond to NBS and NAS, respectively (see Additional File 7). The transcript per million (TPM) values are listed to the right of the transcript IDs. Transcripts from the two species with highly similar sequences are shown in pairs. Transcripts sharing high similarity with NBS and NAS are referred to as the neoculin group (surrounded by a red frame). Groups of other highly similar transcripts are shown in groups 1 and 2. Arrows to the right of the TMP value highlight the ortholog pairs with extremely different TPM values. The sequences and species of origin of the selected GNA family members are as follows: ASA, Allium sativum (1BWU); GNA, Galanthus nivalis (1MSA); and NPL, Narcissus pseudonarcissus (1NPL) were extracted from Protein Data Bank entries. Others sequences were selected from GenBank entries: PRA, Polygonatum roseum (AY899824); PMA, Polygonatum multiflorum (U44775); CMA, Clivia miniata (L16512); ZCA, Zephyranthes candida (AF527385); AAA, Allium ascalonicum (L12172); ACA, Allium cepa (AY376826); AUA, Allium ursinum (U68531); THC, Tulipa hybrid cultivar (U23043); ZOA, Zingiber officinale (AY657021); ACO, Ananas comosus (AY098512); AKA, Amorphophallus konjac (AY191004); DPA, Dioscorea polystachya (AB178475); CHC, Cymbidium hybrid cultivar (U02516); and EHA, Epipactis helleborine (U02515). 

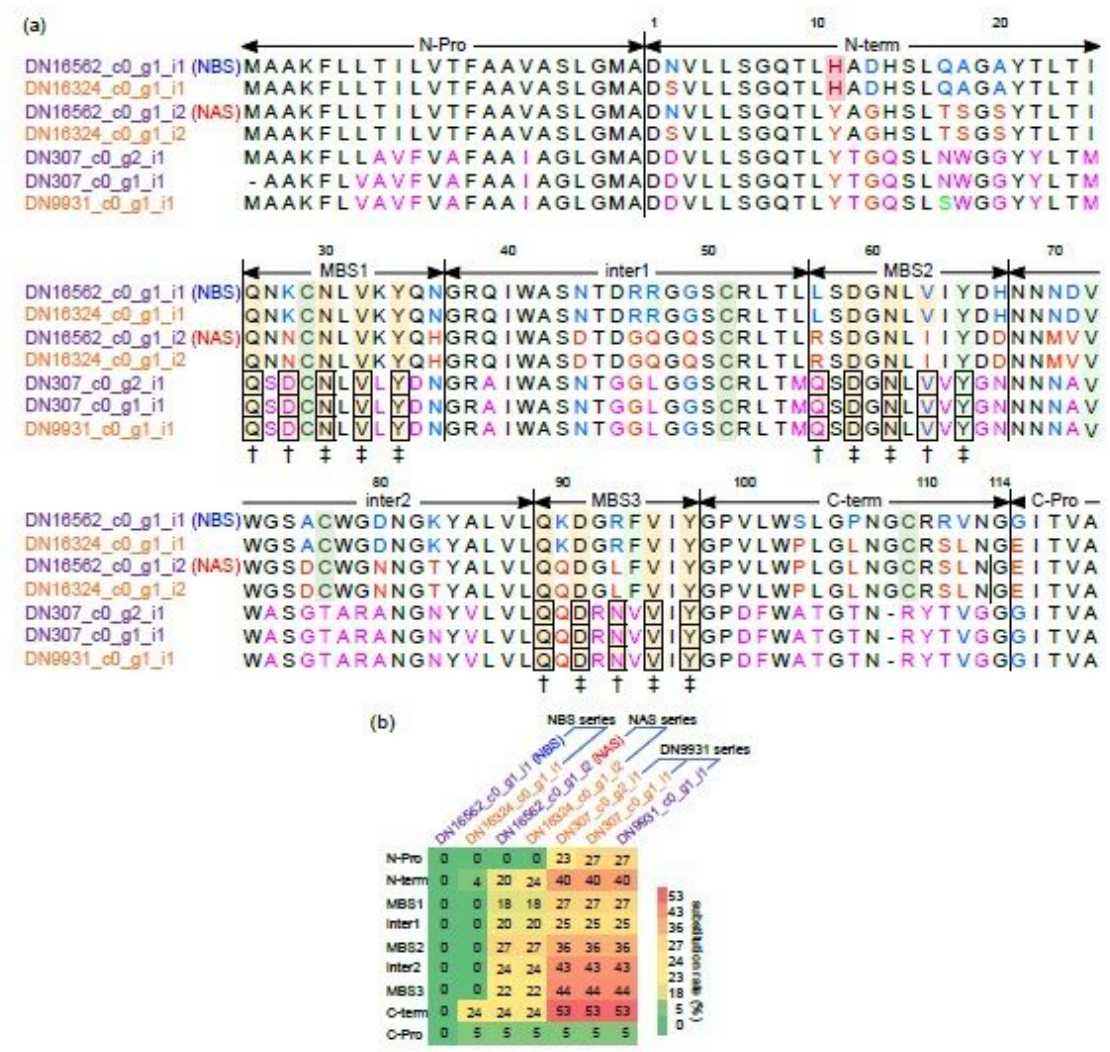

\section{Figure 6}

Comparison of the amino-acid sequences of neoculin group members. (a) Amino-acid sequence alignment of neoculin group members from Curculigo latifolia and C. capitulata fruits. In each alignment, the residues that are consistent with only NBS or only NAS are shown in blue and red, respectively. The residues that are not consistent with NBS or NAS are shown in pink, and those that are consistent with only DN9931_c0_g1_i1 (Ser17) are shown in light green. His11 and cysteine residues are highlighted in dark red and dark green, respectively. Arg48, Tyr65, Val72, and Phe94 are highlighted in pale green. Mannose-binding sites (MBS, QxDxNxVxY) are indicated by a dagger ( + ), and conserved residues are highlighted in yellow. MBS residues that are conserved in all sequences are indicated by a double dagger ( $¥)$. MBS residues of DN307_c0_g2_i1, DN307_c0_g1_i1, and DN9931_c0_g1_i1 are shown in boxes. The transcripts were divided into nine regions, $\mathrm{N}$-Pro, N-term, MBS1, inter1, MBS2, inter2, MBS3, C-term, and C-Pro, based on the regions removed by mRNA processing, the N-or C-terminal regions, the regions of MBS 1 to 3 , and the regions between the MBSs. (b) Amino-acid residue substitutions in neoculin group proteins. The region from inter2 to $\mathrm{C}$-term is the primary region of sequence diversity in the neoculin group. The values shown in heatmap are amino-acid substitution rates (\%) of neoculin group. The NBA sequence was used as the reference sequence. 

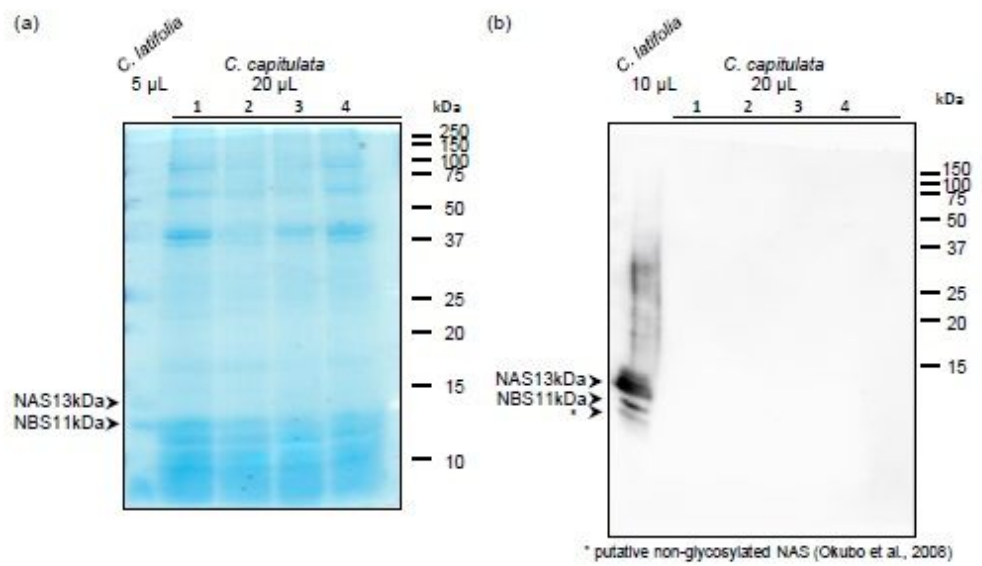

\section{Figure 7}

Biochemical analysis of Curculigo latifolia and C. capitulata fruits. Extracts from one C. latifolia fruit and four C. capitulata fruits were subjected to SDS-PAGE. (a) For CBB staining, $5 \mu \mathrm{L}$ of C. latifolia extract and $20 \mu \mathrm{L}$ of C. capitulata extract were applied to each well. (b) For immunoblotting, $10 \mu \mathrm{L}$ of $\mathrm{C}$. latifolia extract and $20 \mu \mathrm{L}$ of $\mathrm{C}$. capitulata extract were applied to each well. "*" indicates the band thought to be non-glycosylated NAS [38](Okubo et al., 2008).

\section{Supplementary Files}

This is a list of supplementary files associated with this preprint. Click to download.

- AdditionalFile8.pdf

- AdditionalFile7.pdf

- AdditionalFile6.pdf

- AdditionalFile5.pdf

- AdditionalFile4.pdf

- AdditionalFile3.xlsx

- AdditionalFile2.pdf

- AdditionalFile1.pdf 